\title{
Community Managed Protected Areas Conserve Aboveground Carbon Stocks: Implications for REDD+
}

\author{
Camilo Alejo ${ }^{1 *}$, Wayne S. Walker ${ }^{2}$, Seth R. Gorelik ${ }^{2}$ and Catherine Potvin ${ }^{1,3}$ \\ ' Neotropical Ecology Laboratory, Department of Biology, McGill University, Montreal, QC, Canada, ${ }^{2}$ Woodwell Climate \\ Research Center, Falmouth, MA, United States, ${ }^{3}$ Smithsonian Tropical Research Institute, Panama City, Panama
}

OPEN ACCESS

Edited by:

Jun Ma,

Fudan University, China

Reviewed by:

Tan Chen,

Nanjing Institute of Geography and Limnology (CAS), China

Wentao Huang,

Shenyang Agricultural University,

China

Wen Wu,

Northeastern University, China

*Correspondence:

Camilo Alejo

edgar.alejomonroy@mail.mcgill.ca

Specialty section:

This article was submitted to

Forest Disturbance,

a section of the journal

Frontiers in Forests and Global

Change

Received: 01 October 2021

Accepted: 18 January 2022

Published: 04 March 2022

Citation:

Alejo C, Walker WS, Gorelik SR

and Potvin C (2022) Community Managed Protected Areas Conserve Aboveground Carbon Stocks: Implications for REDD+.

Front. For. Glob. Change 5:787978. doi: 10.3389/ffgc.2022.787978
Protected Areas (PAs) represent a broad spectrum of outcomes and governance systems. Among PAs, Community Managed PAs have emerged from communities that are not exclusively indigenous and have developed social organizations to acquire land rights, participate in forest governance, and in some cases, engage in REDD+. However, regardless of the scale or counterfactual, there is no clear consensus about Community Managed PAs' effectiveness in forest conservation and climate change mitigation. Furthermore, previous studies have been devoted to estimating PAs' effects on deforestation before REDD+ projects began to operate. Based on Community Concessions in Petén (Guatemala) and Extractive Reserves in Acre (Brazil), we analyzed Community Managed PAs' temporal and spatial effects on carbon stocks and avoided emissions relative to unprotected lands, other Sustainable Use PAs (IUCN V-VI), and Strict PAs (I-IV). We used carbon density maps, matching methods, geographic discontinuity designs, and sensitivity analysis between 2003 and 2015. After controlling for the influence of market access and agriculture suitability, our analysis shows that Community Managed PAs were more effective than Other Lands (i.e., unprotected) and Sustainable Use PAs, and at least as effective as Strict PAs, in preserving carbon stocks and avoiding emissions. For instance, relative to Other Lands between 2011 and 2015, Community Managed PAs resulted in net avoided emissions of $4.6 \mathrm{tCO} 2-\mathrm{eq} / \mathrm{ha}$ in Petén (Guatemala) and $2.15 \mathrm{tCO}-\mathrm{eq} / \mathrm{ha}$ in Acre (Brazil). While these net avoided emissions were lower than in previous years, they seem to be driven by a reduction in carbon emissions outside Community Managed PAs. Spatially, the boundaries of Community Managed PAs varied across jurisdictions. For example, the boundaries of Acre's Community Managed PAs' have become less effective in avoiding emissions, which translates into reduced effects on conserving carbon stocks. Our results highlight the need to assess temporal effects to exhibit jurisdiction-wide land-use dynamics and spatial effects to identify local land-use pressures emerging inside or around the boundaries of PAs. Our analysis also shows that decentralized governance in Community Managed PAs may contribute to climate change mitigation through REDD+ and forest conservation targets.

Keywords: carbon stocks, avoided carbon emissions, protected areas, forest communities, REDD+, matching analysis, geographic discontinuity designs 


\section{INTRODUCTION}

Protected Areas (PAs) remain as primary interventions for forest conservation (Börner et al., 2020). In practice, PAs represent a broad spectrum of governance systems with outcomes beyond forest conservation (Dudley et al., 2010). To account for the different outcomes of PAs, the IUCN developed a number of categories. Those classified in categories I-IV, or Strict PAs, privilege biodiversity conservation and limit extractive activities through state-based forms of governance. Sustainable Use PAs, classified in categories V-VI, represent a more direct interaction between ecosystems and people, integrating biodiversity conservation and non-industrial extractive activities under more decentralized forms of governance. Since the 1980s, the decentralized governance of some Sustainable Use PAs has resulted in Community Managed PAs, an intervention aiming to reduce the financial costs of conservation and recognize forest communities' livelihoods, management practices, and social organizations (Agrawal et al., 2008). Considering that climate change mitigation through avoided land-use emissions has become a primary goal for PAs (MacKinnon et al., 2011), Community Managed PAs represent an intervention where multiple social and ecological outcomes converge. Despite the potential win-win outcomes of Sustainable Use PAs, especially in those that are Community Managed, their effectiveness in forest conservation and climate change mitigation can be put into question. For example, Walker et al. (2020) found that non-Strict PAs in the Brazilian Amazon were responsible for more than 90\% of forest carbon losses in PAs. Although counterintuitive, the fact that Sustainable Use PAs or Community Managed PAs may exhibit higher carbon losses than Strict PAs does not necessarily imply that they are not effective. Strict PAs might be experiencing low deforestation (and forest degradation) because of their reduced market access and suitability for agriculture (Pfaff et al., 2014). Hence, if the influence of spatial location is considered, are Community Managed PAs effective in forest conservation and climate change mitigation?

To address this question, different studies use quasiexperimental methods to evaluate PAs' effects on forest conservation. The premise of these studies is to remove the influence of market access and agriculture suitability by equating the distribution of spatial location covariates (e.g., distance to cities) in PAs and some counterfactual (Joppa and Pfaff, 2009, 2010). In the tropics, some of these studies have shown that Strict PAs are more effective than Sustainable Use PAs in forest conservation (Ferraro et al., 2013; Nolte et al., 2013; Pfaff et al., 2015b; Jusys, 2018; Bonilla-Mejía and Higuera-Mendieta, 2019; Elleason et al., 2021), while others have shown the opposite (Nelson and Chomitz, 2011; Andam et al., 2013; Blackman et al., 2015). Despite the lack of consensus, the previous studies offer relevant highlights to assess PAs' effectiveness in forest conservation and climate change mitigation. First, an integral assessment of PAs requires measuring their effectiveness not only relative to unprotected Other Lands [i.e., but also relative to other PAs categories (e.g., Andam et al., 2013; Ferraro et al., 2013; Elleason et al., 2021)]. For example, using Other Lands and different PA categories as counterfactuals of Community
Managed PAs. These multiple comparisons are particularly relevant to account for differences in spatial location among Community Managed PAs, Sustainable Use PAs, Strict PAs, and Other Lands (Pfaff et al., 2014, 2015a). Moreover, certain studies focus on the temporal effects. That is, estimating deforestation or regrowth inside and outside PAs for a time period. However, other studies (e.g., Bonilla-Mejía and Higuera-Mendieta, 2019), assess the role of PAs boundaries relative to their surroundings or the spatial effects to elucidate local land-use dynamics. Thus, estimating temporal effects alongside spatial effects may contribute to the integral assessment of PAs (Blackman et al., 2015; Alejo et al., 2021). Nevertheless, few studies evaluate the effectiveness of Community Managed PAs relative to different land tenures through temporal and spatial assessments.

Some quasi-experimental studies have focused on Community Managed PAs. Typically, Community Managed PAs have emerged from communities that are not exclusively indigenous and have developed social organizations to acquire land rights, access to forest livelihoods, and participate in forest governance (Cronkleton et al., 2008). Two foundational research efforts shed light on the effectiveness of Community Managed PAs in the 2000s. Relative to Other Lands, Blackman et al. (2015) established in the Maya Biosphere Reserve (Petén, Guatemala) that Sustainable Use PAs were more effective than Strict PAs in avoiding deforestation, and among Sustainable Use PAs, Community Concessions (a form of Community Manage PAs) were the most effective. Pfaff et al. (2014) provide a similar insight and exhibit that among Strict PAs, Indigenous Territories, and Extractive Reserves (another form of Community Managed PAs), the latter was the only land tenure with significant impacts on avoided deforestation (Pfaff et al., 2014). However, the context of Community Managed PAs in Petén (i.e., Community Concessions) and Acre (i.e., Extractive Reserves) have experienced changes that may have influenced their role in forest conservation and climate change mitigation. In both jurisdictions, new Strict and Sustainable Use PAs have been declared (UNEP-WCMC and IUCN, 2021), creating an even more complex mosaic of PAs and Other Lands. Regarding Petén, some Community Managed PAs have lost their status while others have consolidated and became proponents on a pioneer jurisdictional REDD+ program in 2012 (Hodgdon et al., 2013). In the same year, the state of Acre began to implement a System of Incentives for Environmental Services (SISA) that also includes a pioneer REDD+ program (Rosa Da Conceição and Börner, 2020). Thus, it becomes crucial to provide an updated and integral assessment to this pioneer Community Managed PAs in the context of climate change mitigation and REDD+.

Consequently, our study aims to assess the effectiveness of Community Managed PAs on forest carbon dynamics before and after the adoption of REDD+ programs in 2012 using two case studies: Community Concessions in the Department of Petén (Guatemala) and Extractive Reserves in the State of Acre (Brazil). Particularly, we assess Community Managed PAs' effect on carbon stocks and avoided carbon emissions relative to Other Lands, Sustainable Use PAs, and Strict PAs. Our assessment relies on carbon density maps, matching methods, and geographic discontinuity designs to measure the temporal 
and spatial effects of Community Managed PAs between 2003 and 2015. After controlling for market access and agriculture suitability covariates, our results show that Community Managed PAs in Petén and Acre are temporarily effective in preserving larger carbon stocks and avoiding carbon losses. However, these effects have been reducing in time and becoming less robust to unobserved covariates. The spatial effects indicate that Community Managed PAs' boundaries have varied effects on carbon dynamics related to the geographic settings of Petén (Guatemala) and Acre (Brazil).

Our study differs from previous research on PAs and quasiexperimental methods in multiple ways. Compared with studies that estimate the effectiveness of PAs using either Other Lands (e.g., Nelson and Chomitz, 2011; Alejo et al., 2021) or other PAs (e.g., Elleason et al., 2021) as counterfactuals, we estimate Community Managed PAs' effectiveness relative to multiple land tenures. Moreover, we explore this effectiveness temporarily and spatially on carbon stocks and avoided emissions, contrasting similar studies that usually explore one of these two approaches on deforestation (e.g., Miranda et al., 2016; Blackman and Veit, 2018; Bonilla-Mejía and Higuera-Mendieta, 2019; Baragwanath and Bayi, 2020). Finally, our focus on Community Managed PAs' effects on carbon stocks dynamics exceeds the time frame of previous studies in Petén and Acre (i.e., Pfaff et al., 2014; Blackman, 2015) and explores the influence of forest communities and decentralized governance on climate change mitigation and REDD+.

\section{MATERIALS AND METHODS}

\section{Study Areas}

Our study assesses Community Managed PAs in two subnational jurisdictions from the Neotropics: Petén, a department in northern Guatemala, and Acre, a state in Brazil's western Amazon (Figure 1 and Supplementary Table 1). The predominant ecosystems are two types of tropical moist forests: the PeténVeracruz for the former and the Southwest Amazon for the latter (Olson et al., 2001). Petén and Acre correspond to particular social, political, and geographic settings, but share at least, four factors in common: (1) policies and investments in forest conservation for more than three decades, (2) diverse land tenures involved in forest governance, (3) social organizations that emerged from forest communities, and (4) being pioneers in REDD+ programs.

In Petén, the Maya Biosphere Reserve was established in 1990 under the pressure of environmental and international aid organizations to curb deforestation, resulting in the delimitation of strict PAs, Multiple Use Zones (here, Sustainable Use PAs), and a buffer zone (Radachowsky et al., 2012). The new reserve created tensions between the PAs service (CONAP) and past-resident communities (Cronkleton et al., 2008). These tensions escalated with the arrival of new residents after the Guatemalan peace accords and the interest of private enterprises to acquire forest concessions in Multiple Use Zones (Cronkleton et al., 2008). Supported by environmental and international aid organizations, ACOFOP (“Asociación de Comunidades Forestales de Petén”) emerged as a social organization to negotiate the access of past, new resident, and non-resident communities to forest concessions and guarantee local livelihoods (Millner et al., 2020). Between 1994 and 2002, the negotiations granted access to Multiple Use Zones in the Maya Biosphere Reserve to community concessions, private concessions, and cooperatives (Radachowsky et al., 2012). More recently, the department of Petén extended its PAs network outside the Maya Biosphere Reserve with public and private areas with strict protection (IUCN I-IV) and sustainable use (IUCN V-VI) (UNEP-WCMC and IUCN, 2021). We classify these multiple land tenures in different PA categories (Table 1). PAs that allow indirect uses (IUCN I-IV) are defined as Strict PAs. PAs with IUCN categories $\mathrm{V}-\mathrm{VI}$ and revoked community concessions, cooperatives, and Multiple Use Zones in the Maya Biosphere Reserve are categorized as Sustainable Use PAs. The Maya Biosphere Reserve's buffer zone, which does not fit our definitions of PAs, and Private Concessions, which belong to ACOFOP but do not involve forest communities, are excluded from our study. We focus on eight Community Managed PAs, here defined as Community Concessions in the Maya Biosphere Reserve that have remained active and certified. Among these Community Managed PAs, one is inhabited by new residents (Cruce a la Colorada), two by past residents (Carmelita and Uaxactún), and the rest belong to non-resident communities that live outside the Maya Biosphere Reserve. Also relevant for our study, these Community Managed PA's became proponents with the PAs service (CONAP) of the REDD+ program GuateCarbon since 2012 (Hodgdon et al., 2013). GuateCarbon aims to offset 33 million tons of CO2-eq from avoided deforestation over a 30-year life span applying a baseline that involves the department of Petén and models future deforestation based on key variables such as roads, population density, markets, and development plans (Hodgdon et al., 2013; Verra, 2017).

The state of Acre in the Brazilian Amazon has also developed conservation policies and social organizations that emerged from forest communities. During the 1970's the expansion of cattle ranching and land speculation in the Brazilian amazon created conflicts with rubber tappers and concern among environmental organizations (Cronkleton et al., 2008; Rosa Da Conceição and Börner, 2020). A converging pressure from environmental organizations, the growing social movement of rubber tappers to defend their lands and livelihoods, and the later assassination of rubber tapper leader Chico Mendes in 1988 influenced the creation of two federal Extractive Reserves in Acre (Rosa Da Conceição and Börner, 2020). Since the 1990s, the state of Acre developed policies that incentivized investments in sustainable economic activities, economic and ecological zoning (Pfaff et al., 2014), and in 2010 established the System of Incentives for Environmental Services (SISA) that relies on international and national funding (Sills et al., 2014; Rosa Da Conceição and Börner, 2020). This system includes a pioneer jurisdictional REDD+ program, ISA-Carbono, which involved payments for demonstrated emission reductions between 2012 and 2015 for the first implementation phase (Sills et al., 2014; Rosa Da Conceição and Börner, 2020). Since 2017, the second phase of ISA-Carbono has been under implementation (IMC, 2020). The 


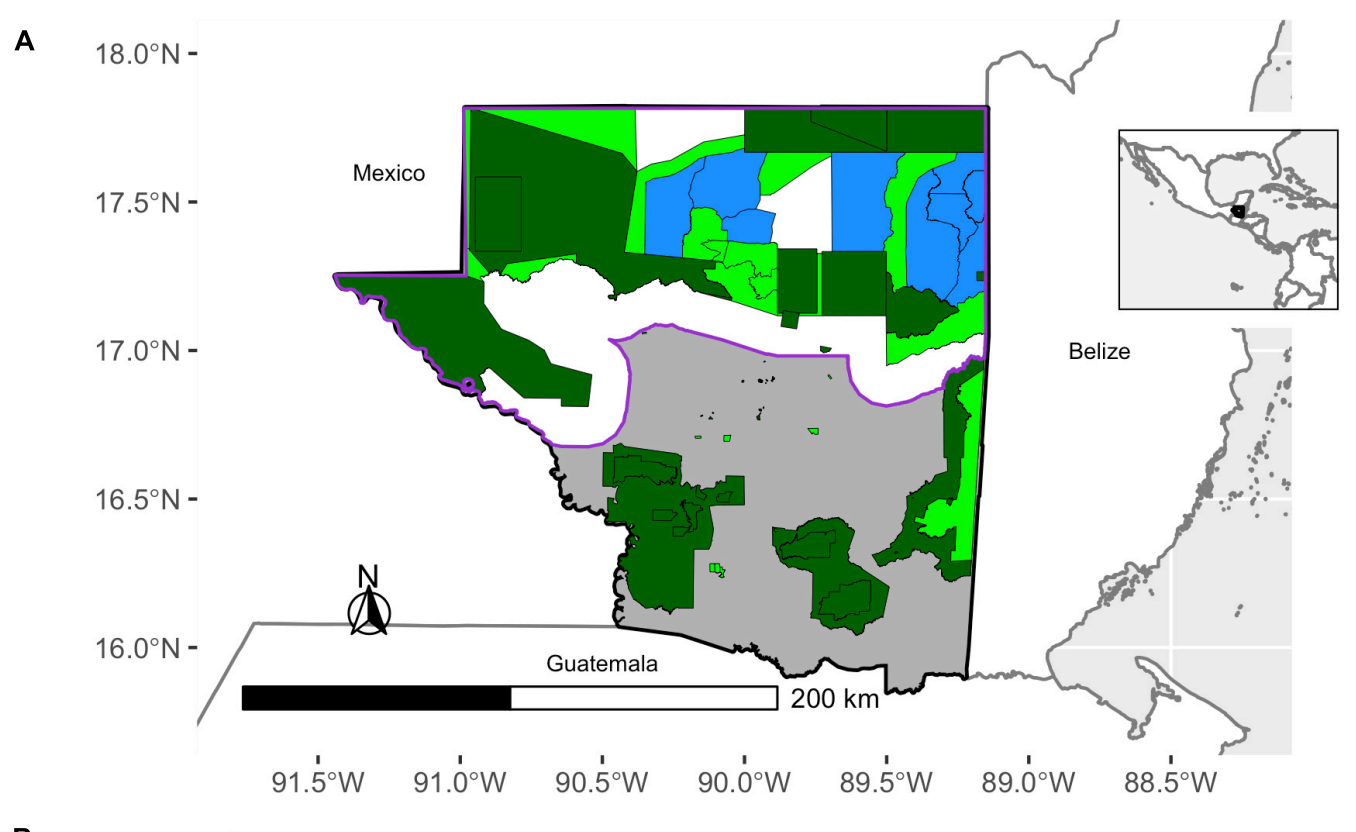

B

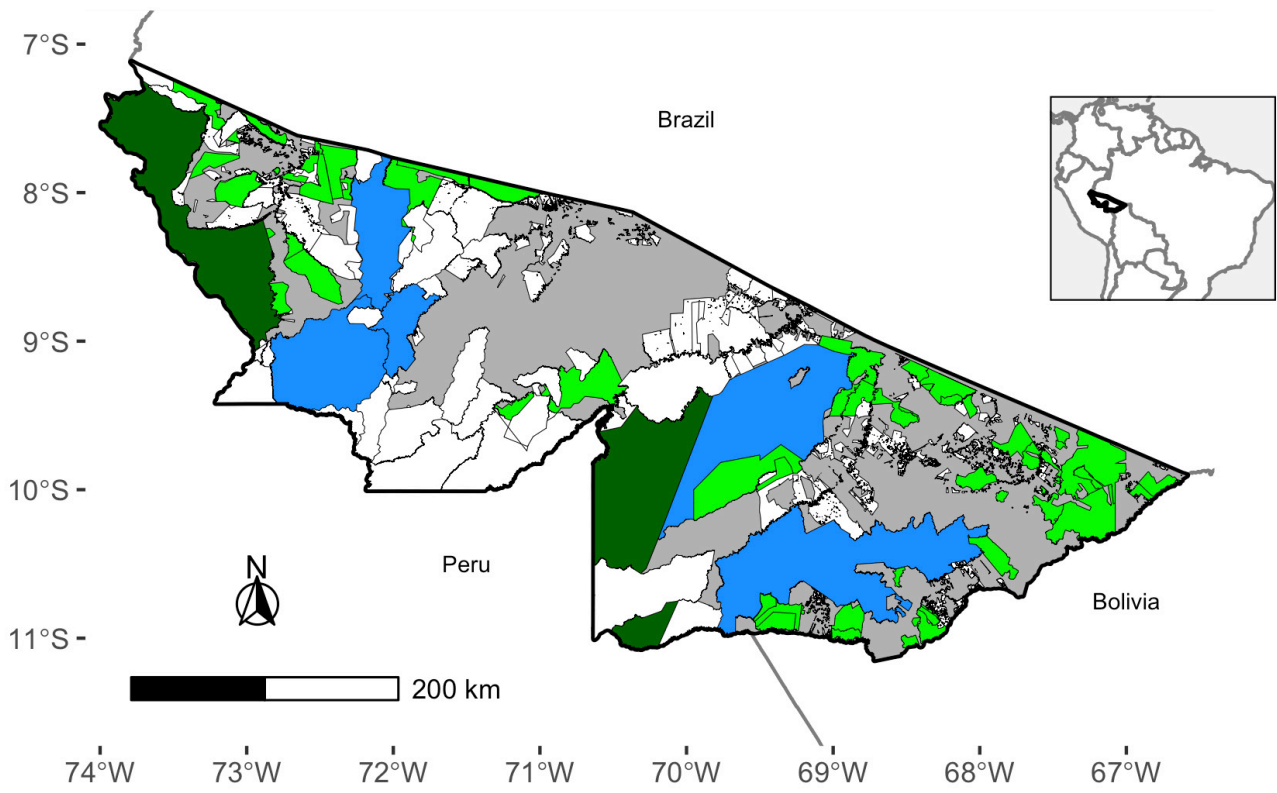

Community Managed PAs

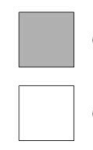

Other Lands

Sustainable Use PAs (IUCN V-VI or eq.)

Maya Biosphere Reserve

Strict PAs (IUCN I-IV)

Other Protected Lands

FIGURE 1 | Study areas. (A) The department of Petén in Guatemala (Central America). (B) The state of Acre in Brazil (South America). Land tenure is classified as Community Managed PAs (blue), which correspond to Community Concessions in Petén and Extractive Reserves in Acre, Other Lands (gray), Sustainable Use PAs (light green), Strict PAs (dark green), and Other Protected Lands (white).

program includes as beneficiaries forest extractivists (including rubber tappers), indigenous communities, and small colonist farmers (Sills et al., 2014). Furthermore, these policies led to the declaration of multiple PAs, including strict PAs (IUCN V-VI) such as National Parks, State Parks, and Environmental Protection Areas. There is also a diverse group of PAs that allow sustainable use, here defined as Sustainable Use PAs, including IUCN VI PAs (e.g., National and State forests) and settlements in public forests that lack an IUCN status. Considering that our study focuses on non-indigenous forest communities, we do not assess Indigenous Territories and their overlaps with PAs. Undesignated public forests are also excluded from the study 
TABLE 1 | Protected Areas (PAs) categories included in the department of Petén (Guatemala) and the state of Acre (Brazil).

\begin{tabular}{|c|c|c|c|c|}
\hline \multirow[b]{2}{*}{ Jurisdiction } & \multicolumn{4}{|c|}{ Protected Areas (PAs) } \\
\hline & $\begin{array}{c}\text { Community Managed (IUCN } \\
\text { IV-VI or equivalent) }\end{array}$ & Sustainable Use (IUCN IV-VI or equivalent) & $\begin{array}{l}\text { Strict (IUCN I-IV } \\
\text { or equivalent) }\end{array}$ & $\begin{array}{l}\text { Other Protected Lands } \\
\text { (Excluded from the study) }\end{array}$ \\
\hline \multirow[t]{7}{*}{ Petén (Guatemala) } & Community Concessions (Active) $)^{1,2}$ & $\begin{array}{l}\text { Community Concessions (revoked or } \\
\text { suspended managed plans) })^{1,2}\end{array}$ & National Parks & Private Concessions ${ }^{1,2}$ \\
\hline & $\begin{array}{l}\text { San Andrés, Carmelita, Cruce a la } \\
\text { Colorada, Uaxactún, Chosquitán, } \\
\text { Las Ventanas, La Unión, Yaloch }\end{array}$ & Special use zones - ZUM ${ }^{1,2}$ & $\begin{array}{l}\text { Regional Municipal } \\
\text { Park }\end{array}$ & Buffer Zone ${ }^{1,2}$ \\
\hline & & Cooperatives $^{1,2}$ & Wildlife refugee & \\
\hline & & Private Natural Reserves & Protected Biotopes & \\
\hline & & Biosphere Reserves & Biological Reserves & \\
\hline & & & Natural Monuments & \\
\hline & & & $\begin{array}{c}\text { Cultural } \\
\text { Monuments }\end{array}$ & \\
\hline \multirow[t]{7}{*}{ Acre (Brazil) } & Extractive Reserves (RESEX) & National Forests & National Parks & Indigenous Territories ${ }^{2}$ \\
\hline & $\begin{array}{c}\text { Chico Mendes, Cazumbá-Iracema, } \\
\text { Alto Juruá, Alto Tarauacá, Riozinho } \\
\text { da Liberdade }\end{array}$ & State Forests & State Parks & $\begin{array}{c}\text { Indigenous Territories/PAs } \\
\text { overlaps }\end{array}$ \\
\hline & & Environmental Protection Area & $\begin{array}{l}\text { Area of relevant } \\
\text { ecological interest }\end{array}$ & Undesignated Public Forests ${ }^{2}$ \\
\hline & & Directed Settlement Projects - PAD 2,3 & Ecological Station & \\
\hline & & Agroextractive Settlement Project - PAE 2,3 & & \\
\hline & & Sustainable Development Project - PDS 2,3 & & \\
\hline & & Forest Settlement Project - PAF ${ }^{2,3}$ & & \\
\hline
\end{tabular}

Community Managed PAs are a subcategory of Sustainable Use PAs that was analyzed independently.

${ }^{1}$ Maya Biosphere Reserve.

${ }^{2}$ No official IUCN category.

${ }^{3}$ Settlements in Public Forests.

because they are not considered PAs (Serviço Florestal Brasileiro, 2020). As active Community Concessions in Petén (Guatemala), we define Extractive Reserves in Acre (Brazil) as Community Managed PAs, given the relatively unified social organizations behind the establishment of these areas (Cronkleton et al., 2008; Gomes et al., 2018; Millner et al., 2020). We include the following five Extractive Reserves in our study: Chico Mendes, CazumbáIracema, Alto Juruá, Alto Tarauacá, and Riozinho da Liberdade. Finally, any public and private land that is not categorized as PA, buffer zone, Indigenous Territory, or Private Concessions was defined as Other Land.

\section{Spatial Data and Processing}

PAs and other land tenures were spatially delineated from multiple sources (Table 2). The World Database on Protected Areas (UNEP-WCMC and IUCN, 2021) was used to establish the boundaries and IUCN categories of Strict PAs and some Sustainable Use PAs in Petén (Guatemala) and Acre (Brazil). The boundaries and status of Community Managed PAs (i.e., Community Concessions) and Sustainable Use PAs in the Maya Biosphere Reserve (Petén) were confirmed from data curated by ACOFOP. Indigenous Territories and their overlaps with PAs in Acre were defined from data curated by RAISG (Amazon Georeferenced Socio-Environmental Information Network). The "Cadastro Nacional de Florestas Públicas" (National survey of public forests) from the Brazilian government allowed to identify settlements in public forests (Sustainable Use PAs) and undesignated public forests (Serviço Florestal Brasileiro, 2020).
These geospatial datasets defined land tenure and, therefore, the treatment group (i.e., Community Managed PAs) and control groups (Other Lands, Sustainable Use PAs, and Strict PAs).

In our statistical analyses, annual carbon stocks and avoided land-use carbon emissions were the response variables. We determined carbon stocks dynamics in both Petén (Guatemala) and Acre (Brazil) from annual carbon density maps $(\sim 500 \mathrm{~m}$ resolution) generated by the Woodwell Climate Research Centre between 2003 and 2015 (Baccini et al., 2021) and explained in detail by Baccini et al. (2012, 2017) and Walker et al. (2020). This time frame is segmented in three time periods: 20032007, 2008-2011, and 2012-2015. The first period is Pre-REDD+ considering that the program was launched at the Bali COP in 2007. We define the second period as REDD+-Readiness due to the international coordination that led to MRV systems (Monitor, Report, and Verify) and safeguards that influenced the design of GuateCarbon in Petén (Guatemala) and ISA-Carbono in Acre (Brazil) before 2012. Finally, the latest period, REDD+ implementation, corresponds to the beginning of the crediting period of GuateCarbon and the first payments for demonstrated emission reductions in ISA-Carbono.

Agriculture suitability and market access conditions were used as spatial location covariates associated with carbon stocks dynamics in Petén (Guatemala) and Acre (Brazil) (Table 2). Elevation, slope, precipitation, and temperature were included as spatial location covariates involved in agricultural suitability, following previous quasi-experimental studies (Pfaff et al., 2014; Blackman, 2015; Blackman and Veit, 2018; Alejo et al., 2021). 
TABLE 2 | Geospatial data included in the study.

\begin{tabular}{|c|c|c|c|}
\hline Jurisdiction & Geospatial information & Time period & Source \\
\hline \multirow[t]{2}{*}{ Petén (Guatemala) } & $\begin{array}{l}\text { Community Concessions, Private } \\
\text { Concessions, and Cooperatives }\end{array}$ & 2002-2018 & ACOFOP \\
\hline & Protected Areas & $2002-2020$ & UNEP-WCMC and IUCN (2021) \\
\hline \multirow[t]{2}{*}{ Acre (Brazil) } & Indigenous Territories & $2002-2018$ & $\begin{array}{l}\text { RAISG (Red Amazónica de Información Socioambiental } \\
\text { Georeferenciada) }\end{array}$ \\
\hline & Protected Areas & 2002-2015 & $\begin{array}{l}\text { RAISG, Serviço Florestal Brasileiro (2020), UNEP-WCMC and IUCN } \\
\text { (2021) }\end{array}$ \\
\hline \multirow[t]{6}{*}{ Both jurisdictions } & Annual carbon density (tC/ha) & $2003-2015$ & Woodwell Climate Research Center (Baccini et al., 2012, 2017, 2021) \\
\hline & Elevation (m) and slope (deg.) & NA & CGIAR-SRTM V4 (Reuter et al., 2007; Jarvis et al., 2008) \\
\hline & $\begin{array}{l}\text { Mean precipitation ( } \mathrm{mm} / \text { year }) \text { and mean } \\
\text { temperature }\left({ }^{\circ} \mathrm{C} / \text { year }\right)\end{array}$ & 1970-2000 & WorldClim V2.1 (Fick and Hijmans, 2017, 2020) \\
\hline & $\begin{array}{l}\text { Population density - UN adjusted } \\
\text { (people } / \mathrm{km}^{2} \text { ) }\end{array}$ & 2002, 2007, 2011 & $\begin{array}{l}\text { Worldpop and Center for International Earth Science Information } \\
\text { Network (CIESIN) (2020) }\end{array}$ \\
\hline & $\begin{array}{l}\text { Travel time to the nearest city of } 50,000 \\
\text { or more people }\end{array}$ & 2000 & Nelson (2008) \\
\hline & $\begin{array}{l}\text { Travel time to the nearest city of } 50,000 \\
\text { or more people }\end{array}$ & 2015 & Weiss et al. (2018) \\
\hline
\end{tabular}

Elevation and slope were obtained from CGIAR-SRTM Version 4 (Reuter et al., 2007; Jarvis et al., 2008). 30-year (19702000) mean average precipitation and temperature were obtained from WorldClim's Version 2.1 (Fick and Hijmans, 2017, 2020). Additionally, we included population density and travel time to the nearest city, which have been used to control the influence of market access (Nelson and Chomitz, 2011; Negret et al., 2020). We determined population density in 2002, 2007 and 2011 from the WorldPop database [Worldpop, and Center for International Earth Science Information Network (CIESIN), 2020]. Travel time to cities with more than 50,000 people was obtained from Nelson (2008) in 2000 and Weiss et al. (2018) in 2015. By resampling tenure and covariate data to carbon density maps' spatial resolution ( $\sim 500 \mathrm{~m})$, we created observation units with carbon density estimates, land tenure, and covariates. The Supplementary Material summarizes the carbon stocks (Supplementary Table 2), total carbon storage (Supplementary Table 3), agriculture suitability (Supplementary Table 4), and market access data (Supplementary Table 5) for each jurisdiction and land tenure. All geoprocessing was performed with the $\mathrm{R}$ packages sf (Pebesma et al., 2021a) and stars (Pebesma et al., 2021b).

\section{Matching Analysis}

To control for spatial location and infer the effectiveness of Community Managed PAs on carbon stocks dynamics relative to Other Lands, Sustainable Use PAs, and Strict PAs, we performed matching analysis and linear mixed models following Alejo et al. (2021). Matching analysis removes heterogeneous observations and creates a subset of treatment and control observations with similar covariate values, reducing the association of a treatment variable with covariates (Diamond and Sekhon, 2012). Here, the treatment variable corresponded to areas designated as Community Managed PAs, and matching created subsets of observations in the treatment and control (i.e., Other Lands, or Sustainable Use PAs, or Strict PAs) with similar slope, elevation, precipitation, temperature, population density, and time travel to cities. Thus, matching analysis was applied to compare Community Managed PAs with Other Lands, Sustainable Use PAs, and Strict PAs independently. Additionally, matching analysis was performed in the three time periods aforementioned: 2003-2007, 2008-2011, and 2012-2015. Each matching analysis only included PAs that were established at least a year before a time period. It is worth noting that the extent of Community Managed PAs increased $5.5 \%$ during the second time period in Acre but did not vary in Petén (Supplementary Table 1). Similarly, population density estimates corresponded to the previous year in a time period (e.g., 2002 population density to 2003-2007). Regarding time travel to cities, the 2000's estimates were applied for the periods 2003-2007 and 2008-2011, while the 2015's estimates were applied for 2012-2015. Using different time periods guarantees an accurate, updated, and conservative assessment of Community Managed PAs' performance that accounts for changes in land tenures extents and changing conditions in covariates. All matching analyses were performed through coarsened exact matching (CEM) (Iacus et al., 2015) in the R package MatchIt (Ho et al., 2015) that allows users to define intervals of equivalent covariate values. For instance, the travel time to cities was restricted to 60 min intervals, making traveling times between 61 and 120 min "equivalent." CEM's approach created a subset of observations with a covariate balance between Community Managed PAs (i.e., the treatment) and each control in Petén (Guatemala) and Acre (Brazil). The unmatched and matched covariate balances were assessed through standardized mean differences and variance ratios (Stuart, 2010) using the $\mathrm{R}$ package Cobalt (Greifer, 2021).

\section{Temporal Effects on Carbon Stocks Dynamics}

After matching analysis, we used linear mixed models to estimate the temporal effect of Community Managed PAs on carbon stocks and avoided carbon emissions relative to Other Lands, 
Sustainable Use PAs, and Strict PAs. The effects of Community Managed PAs on carbon stocks derived from the general expression:

$$
y_{t}=b_{0 t}+b_{1 t} x_{p}+\beta Z_{p}+\alpha_{p}+e_{t}
$$

Where $y_{t}$ corresponded to carbon density in year $t$, the outcome variable, and $b_{0 t}$ was the fixed intercept. $\mathrm{b}_{1 t}$ and $x_{p}$ were the fixed effect slope in year $t$ and predictor of the treatment in the period $p$ (i.e., a dummy for Community Managed PAs), respectively. $\beta$ was a vector of additional fixed effects for a vector of predictors $Z_{p}$, containing the covariates elevation, slope, temperature, precipitation, population density, and travel time to cities. Including the covariates as fixed effects span any remaining imbalances from the matched subsets, providing further control on the influence of market accessibility and agricultural suitability, and therefore, conservative estimates of Community Managed PAs' effects on carbon stocks dynamics. The matched sub-group (matched observation units in treatments and control with similar covariate values) was the random effect $e_{t}$ to account for the structure of the matched subsets. We slightly modified the previous expression to calculate the avoided carbon emissions as:

$$
\Delta y_{p}=b_{0 p}+b_{1 p} x_{p}+\beta Z_{p}+\alpha_{p}+e_{p}
$$

In this case, $\Delta y_{p}$ represents the net change in carbon density for a time period $p$ of 4 years. The linear mixed models in (1) were estimated annually in 2007, 2011, and 2015 and the linear mixed models in (2) were estimated in 2003-2007, 20072011, and 2011-2015.

We focused on two parameters in (1) and (2) to estimate the temporal effect of Community Managed PAs on carbon stocks and avoided carbon emissions. The fixed effects intercept $b_{o t}$ in (1) refers to the average annual carbon density found in the controls (i.e., Other Lands, Sustainable Use PAs, or Strict PAs) and represent the carbon stocks baselines for Community Managed PAs. $b_{1 t}$ (1) refers to the annual average differences of carbon stocks between the treatment (i.e., Community Managed PAs) and the controls. Thus, a positive effect in (1) implies that Community Managed PAs would store higher carbon stocks than a given control after controlling for spatial location. Regarding (2), the fixed effects intercept $b_{o p}$ refers to the average change in carbon density found in the controls. $b_{1 p}$ (2) compares the average change of carbon stocks in the treatment and the control group over a 4 years period. A positive effect in (2) transformed to $\mathrm{CO}_{2}$-eq implies that Community Managed PAs avoided more carbon emissions than a given control after controlling for spatial location. In other words, the temporal effects derived from the matching analysis together with the linear mixed models allowed us to estimate if Community Managed PAs stored larger carbon stocks and avoided more $\mathrm{CO}_{2}$-eq emissions than Other Lands, Sustainable Use PAs, and Strict PAs.

\section{Spatial Effects on Carbon Stocks Dynamics}

To estimate the spatial heterogeneity of the temporal effects, we used geographic discontinuity designs. Following
Keele and Titiunik (2015) and similar to Alejo et al. (2021), the geographic discontinuity designs aimed to estimate the effect of Community Managed PAs boundaries on preserving carbon stocks and avoiding $\mathrm{CO}_{2}$-eq emissions (hereafter, spatial effects) relative to surrounding Other Lands, Sustainable Use PAs, and Strict PAs. These geographic discontinuity designs are based on two assumptions. First, the treatment assignment occurs as-if randomized when controlling for covariates and geographic distance (i.e., the distance among treatment and control observations throughout a boundary) (Keele et al., 2015). Derived from the first assumption, the second assumption establishes that the spatial effect is a function of the treatment of interest (Keele and Titiunik, 2015), implying that Community Managed PAs boundaries influence carbon stocks and $\mathrm{CO}_{2}$-eq emissions.

The assumptions above were supported by employing CEM to find treatment and control observations with the equivalent covariates (i.e., slope, elevation, temperature, precipitation, population density, and travel time to the nearest city) and additionally including the geographic distance. Particularly, we controlled for geographic distance by performing matching analyses throughout four buffer zones inside and outside the boundaries of Community Managed PAs: $0-1,0-5,0-10$, and $0-15 \mathrm{~km}$. We chose these distances based on previous studies showing that natural vegetation (Joppa et al., 2008) and carbon stocks (Alejo et al., 2021) increase inside the boundaries of PAs and stabilize at $\sim 15 \mathrm{~km}$. Thus, when matching treatment and control observations in buffer zones $0-1 \mathrm{~km}$, we included matches across a $2-\mathrm{km}$ radius. Similarly, in 0-15-km buffer zones, we matched observations across a $30-\mathrm{km}$ radius.

As the temporal effects, the covariate balance before and after matching in the four buffer zones was assessed through standardized mean differences and variance ratios. As suggested by Keele et al. (2015), we provided further support to the geographic discontinuity designs by performing falsification tests. These tests imply that each covariate in $Z_{p}$ was treated as an outcome variable $y_{p}$ according to the linear mixed models above. The falsification tests showed that Community Managed PAs $\left(x_{p}\right)$ had negligible effects on the covariates $\left(b_{1 p}\right)$ after matching. These geographic discontinuity designs guarantee that observations inside and outside the boundaries of Community Managed PAs will occur as-if randomized and be valid counterfactuals by sharing a distance to boundaries (e.g., 0-1 km), covariate values (e.g., 0-60 min travel distance to cities), and geographic distance (e.g., $2 \mathrm{~km}$ radius). Furthermore, if the assumptions above hold across the multiple buffer distances to Community Managed PAs boundaries, it is possible to estimate the heterogeneity of the spatial effects. This heterogeneity represents the variation of carbon stocks and avoided carbon emissions as the distance to Community Managed PAs' boundaries increase.

\section{Sensitivity Analysis}

Combining matching analysis and linear models, like those mentioned above, controls the effects of observed covariates and others unobserved but correlated (Stuart, 2010). We used sensitivity analyses to assess the effect of unobserved covariates unrelated to the observed covariates but related to the treatments 
and their effects (Liu et al., 2013). Specifically, we estimated the $E$-value as applied in Alejo et al. (2021) with the R package $E$ value (Mathur et al., 2021) for all spatial and temporal effects. The $E$-value is a metric that represents the minimum strength that an unmeasured covariate would need to have with the treatment and its effect for the treatment and effect association not to be causal (VanderWeele and Ding, 2017). Following the procedure justified by VanderWeele and Ding (2017), the $E$-value derives from estimating the Effects Ratio (ER), which at the same time derives from the temporal and spatial effects. In our study, the temporal and spatial effects are transformed into an Effects Ratio (ER) (equivalent to a risk ratio in the epidemiological literature) that compares the probability of a positive effect in the treatment with the probability of a positive effect in the control. ERs greater than 1 indicate a greater probability that Community Managed PAs will store higher carbon stocks or avoid larger emissions than Other Lands, Sustainable Use PAs, or Strict PAs. For instance, a hypothetical ER of 2 may imply that Community Managed PAs are two times more likely to avoid higher carbon emissions than Other Lands. Following this hypothetical case, an $E$-value of 3 indicates that the ER of 2 could be explained away by an unmeasured covariate that was associated with both Community Managed PAs and carbon emissions each by three-fold, above and beyond the observed covariates. At the same time, an $E$-value lower than 3 could not alter the ER, and consequently, the temporal effect of Community Managed PAs. In other words, the $E$-value assesses the strength of an unobserved covariate to alter the temporal and spatial effects of Community Managed PAs on carbon stocks dynamics. All geospatial and statistical analyses aforementioned were performed in $\mathrm{R}$ version 4.1.0 (R Core Team, 2021).

\section{RESULTS}

We estimated the effectiveness of Community Managed PAs on carbon stocks dynamics temporarily and spatially relative to Other Lands (i.e., unprotected), Sustainable Use PAs (IUCN V-VI or equivalent), and Strict PAs (IUCN I-IV) in Petén (Guatemala) and Acre (Brazil). Before controlling for market access and agriculture suitability covariates, Community Managed PAs in both jurisdictions throughout 2003 and 2015 stored $>20 \mathrm{tC} / \mathrm{ha}$ compared to Other Lands, $>10 \mathrm{tC} / \mathrm{ha}$ compared to Sustainable Use PAs, and $<10$ tC/ha compared to Strict PAs (Supplementary Table 2). However, these land tenures are not directly comparable, as they are subject to different levels of market access and agriculture suitability (Figure 2 and Supplementary Tables 4, 5). For example, Petén's mean population density in Strict PAs and Other Lands was nearly five times $\left(\sim 11\right.$ people $\left./ \mathrm{km}^{2}\right)$ and ten times $\left(\sim 23\right.$ people $\left./ \mathrm{km}^{2}\right)$ higher than Community Managed PAs $\left(\sim 2.5\right.$ people $\left./ \mathrm{km}^{2}\right)$ in 2002, respectively. Similarly, travel times to cities in 2000 in Acre ranged between $17 \mathrm{~h}$ in Sustainable Use PAs to $39 \mathrm{~h}$ in Community Managed PAs. Furthermore, the influence of these spatial location covariates changes at different paces depending on land tenure. For instance, in Petén, Community Managed PAs travel time to cities in 2015 reduced by 20 min compared to 2000. However, the same comparison in Other Lands led to a reduction of $3 \mathrm{~h}$ in travel time. These differences show that spatial location covariates influencing carbon stocks dynamics even vary among Community Managed PAs and other categories of PAs in Petén and Acre.

\section{Temporal Effects on Carbon Stocks and Avoided Carbon Emissions}

To control the influence of spatial location and estimate the effectiveness of Community Managed PAs on carbon stocks dynamics, we used matching analysis and linear mixed models in three periods of time: 2003-2007, 2007-2011, and 2011-2015 (Figure 2 and Supplementary Figure 1). First, we estimated the temporal effects of Community Managed PAs on annual carbon stocks (Figure 3). These effects describe the annual mean difference of carbon stocks between Community Managed PAs and different land tenures. The temporal effects in 2007, 2011, and 2015 show that Community Managed PAs stored significantly different carbon stocks $(p<0.05)$ compared with Other Lands, Sustainable Use PAs, and Strict PAs. During 2007 Petén's Community Managed PAs stored around $\sim 130 \%$ (44 tC/ha) more carbon stocks than Other Lands. This effect was moderate with Sustainable Use PAs ( 15\%: $8 \mathrm{tC} / \mathrm{ha})$, and Strict PAs ( 5\%; 2 tC/ha). In 2011, these spatial effects increased over all land tenures, but only increased over Strict PAs during 2015 (9.4\%; $6.5 \mathrm{tC} / \mathrm{ha})$. Translated into Effects Ratios, Community Managed PAs in Petén were between 29 and 1.75 times more likely to store higher carbon stocks than Other Lands and Strict PAs in 2015, respectively (Figure 4). According to sensitivity analyses, these temporal Effects Ratios could be explained away by unmeasured covariates with Effects Ratios (i.e., E-values) ranging 50 (Other Lands) and 2.8 (Strict PAs), but weaker unmeasured covariates could not do so. Hence, Community Managed PAs' effects on carbon stocks were robust across different land tenures in Petén.

Compared to Petén, the effects of Community Managed PAs were milder in Acre, and the highest difference on carbon stocks in 2007 occurred with Other Lands $(9.3 \% ; 10 \mathrm{tC} / \mathrm{ha}$ ) followed by Sustainable Use PAs $(6.8 \% ; 8 \mathrm{tC} / \mathrm{ha})$. After 2011, these effects reduced below $2 \%$ (i.e., $4.2 \mathrm{tC} / \mathrm{ha}$ in Other Lands and $3.9 \mathrm{tC} / \mathrm{ha}$ in Sustainable Use PAs), resulting in less robust effects that were more likely to be changed by unobserved covariates (Effects Ratios $=1.08, E$-values $=1.38$ ). Conversely, Community Managed PAs in Acre stored 2.3\% (-4 tC/ha) less carbon than Strict PAs, but this effect increased in $2011(-1.26 \% ;-2 \mathrm{tC} / \mathrm{ha})$ and $2015(-1 \% ;-1.5 \mathrm{tC} / \mathrm{ha})$. These findings suggest that Community Managed PAs in both jurisdictions maintained higher carbon stocks than the other land tenures throughout 2007, 2011 and 2015, except when compared to Strict PAs in Acre. Moreover, Petén's Community Managed PAs have increased their effect on carbon stocks, whereas Acre's tended to reduce theirs.

In addition to estimating Community Managed PAs temporal effects on carbon stocks, we estimated their temporal effects on avoided CO2 equivalent emissions (Figure 5). These effects derive from the differences in carbon stock changes between Community Managed PAs and different land tenures in the 

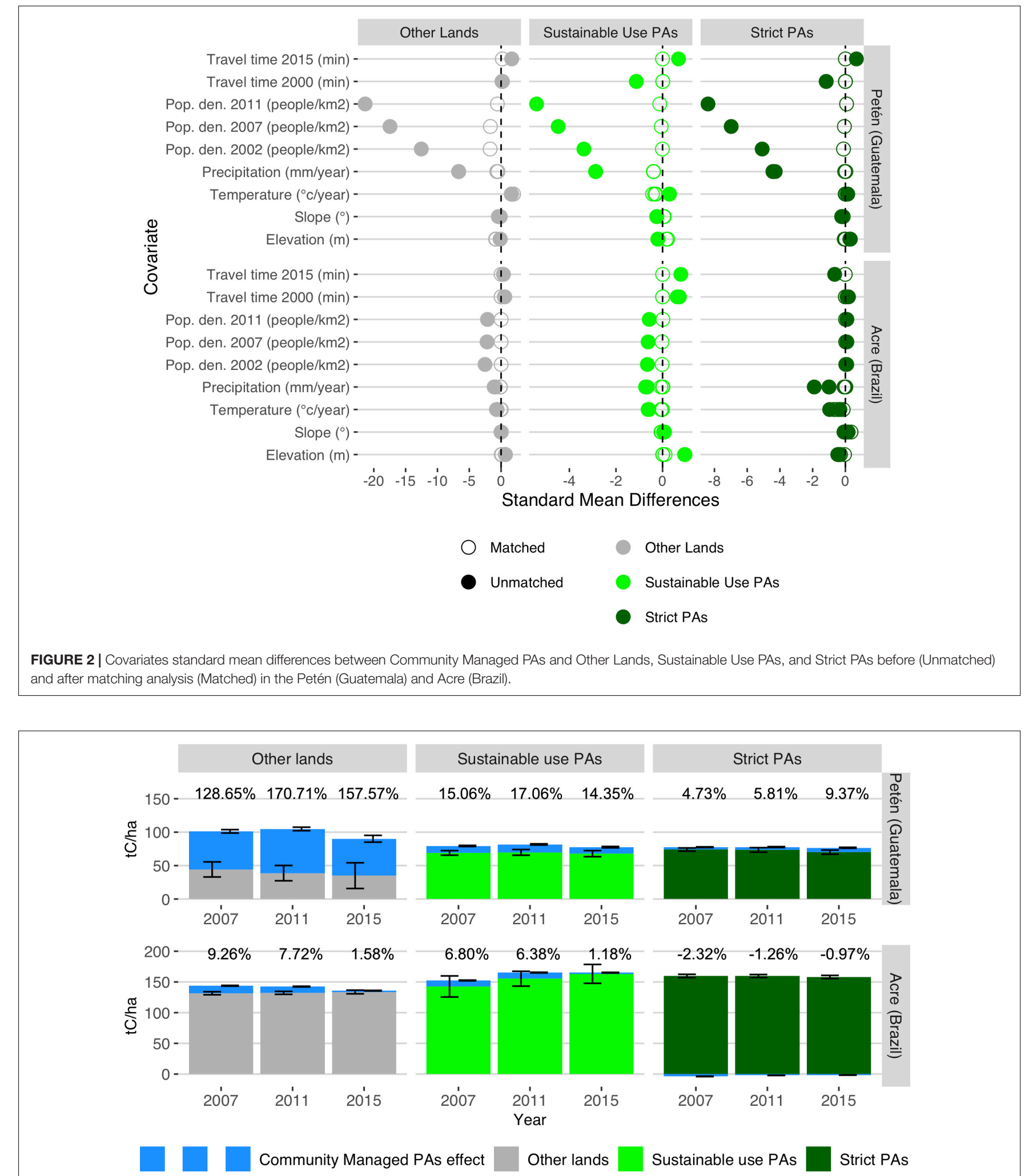

FIGURE 3 | The temporal effects of Community Managed PAs on carbon stocks in Petén (Guatemala) and Acre (Brazil). Significant $(p<0.05)$ temporal effects are represented as blue bars and percentages, indicating the additional/fewer carbon stocks secured by Community Managed PAs relative to the carbon stocks baselines of Other Lands (gray), Sustainable Use PAs (light green), and Strict PAs (dark green). Error bars indicate 95\% confidence intervals for the baselines and temporal effects. 


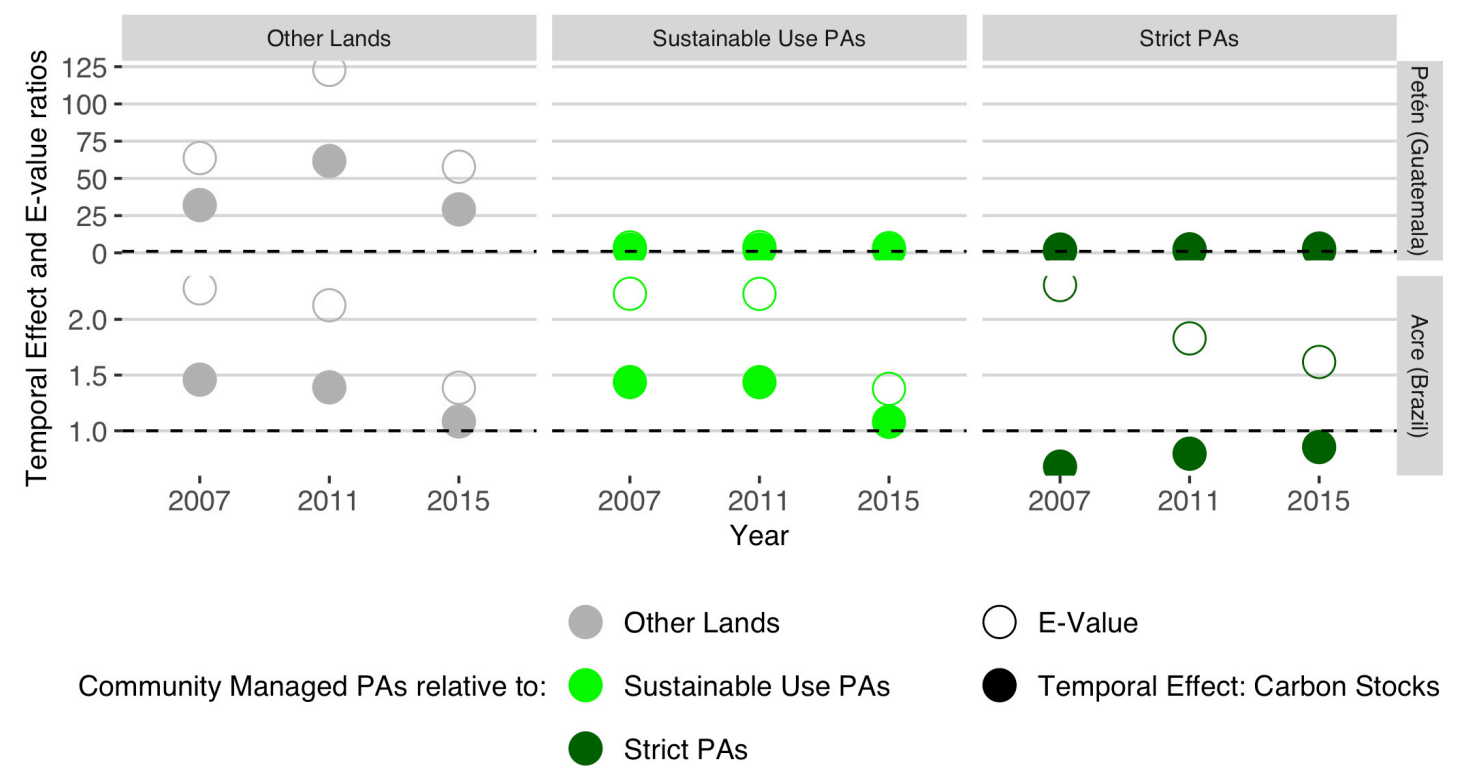

FIGURE 4 | Sensitivity analysis in the temporal effects of Community Managed PAs on carbon stocks in Petén (Guatemala) and Acre (Brazil). The temporal effect ratio (unitless) is equivalent to the probability of a positive temporal effect in the treatment (i.e., Community Managed PAs) divided by the probability of a positive temporal effect in the controls (i.e., Other Lands, Sustainable Use PAs, and Strict PAs). The E-value represents the minimum strength that an unmeasured covariate would need to have with the treatment and the temporal effect for the treatments and temporal effect association not to be causal.

periods 2003-2007, 2007-2011, and 2011-2015. After controlling for covariates, the results exhibit that Community Managed PAs in Petén and Acre have a significant net effect on avoided carbon emissions $(p<0.05)$. For Petén, Community Managed PAs avoided more carbon emissions than Other Lands ( $\sim 47 \mathrm{tCO} 2-$ eq/ha), Sustainable Use PAs (9.3 tCO2-eq/ha) and Strict PAs (4.3 tCO2-eq/ha) throughout the period 2003-2007. In the period 2007-2011, these effects reduced more than half relative to Other Lands ( 19 tCO2-eq/ha) and Strict PAs (1.59 tCO2-eq/ha). Further reductions in 2011-2015 resulted in effects that ranged between 4.6 tCO2-eq/ha (Other Lands) and 1.95 tCO2-eq/ha (Strict PAs). When translated into Effects Ratios (Figure 6), Petén's Community Managed PAs were 3.4 times more likely to avoid carbon emissions than Other Lands in the period 20032007. To explain away these effects, unobserved covariates would have required effect ratios (i.e., E-value) of at least 5.85 . In this case, the Effects Ratio and E-values in the period 2011-2015 reduced to 1.3 and 1.92 , respectively. Similarly, the temporal effects over Sustainable Use and Strict PAs in Petén were slightly less robust (Effects Ratios of 1.17 and 1.33, respectively) to unobserved covariates ( $E$-values of 1.90 and 1.5 , respectively) in the period 2011-2015. These findings imply that reductions in avoided carbon emissions result in less robust effects to unobserved covariates.

As Community Managed PAs in Petén, their effects in Acre were significant on avoided carbon emissions (Figure 5). Between 2003 and 2007, Community Managed PAs in Acre resulted in net avoided emissions compared to Other Lands ( 8 tCO2-eq/ha), Sustainable Use PAs (7.2 tCO2-eq), and Strict PAs (1.7 tCO2-eq). Except for Strict PAs (1.8 tCO2-eq/ha), these effects decreased in relation to Other Lands (3.2 tCO2-eq/ha) and Sustainable Use
PAs (5.8 tCO2-eq/ha) during 2007-2011. The same comparison between 2011 and 2015 resulted in further decreases. Community Managed PAs from Acre avoided emissions of 2.15 tCO2eq/ha (Other Lands), 3.75 tCO2-eq/ha (Sustainable Use PAs), and $0.98 \mathrm{tCO} 2-\mathrm{eq} / \mathrm{ha}$ (Strict PAs). Expectedly, a reduction in avoided carbon emissions results in less robust effects that could be explained away by unobserved covariates (Figure 6). For example, Community Managed PAs were 1.18 times more likely to avoid carbon emissions than Other Lands in 20032007 , and only an effect on unobserved covariates of 1.6 (i.e., $E$-value) or higher could explain away this association. During 2011 and 2015, those values dropped to an Effects Ratio of 1.08 and $E$-value of 1.35 . These temporal effects indicate that Community Managed PAs in Petén and Acre conserved carbon stocks by avoiding more carbon emissions than Other Lands, Sustainable Use PAs, and Strict PAs. Moreover, these effects and their robustness toward unobserved covariates tended to reduce throughout 2007-2011 and 2011-2015. Nevertheless, the reduced effects of Community Managed PAs seem to be driven by a reduction in carbon emissions throughout Other Lands, Sustainable Use PAs, and Strict PAs (Supplementary Figure 2).

\section{Spatial Effects on Carbon Stocks and Avoided Emissions}

We further assessed the effectiveness of Community Managed PAs by exploring their carbon stocks and avoided emissions relative to their surroundings after controlling for spatial location (Supplementary Figures 3-5) through geographic discontinuity designs. Specifically, these spatial effects compared the carbon stocks and avoided emissions inside and outside 

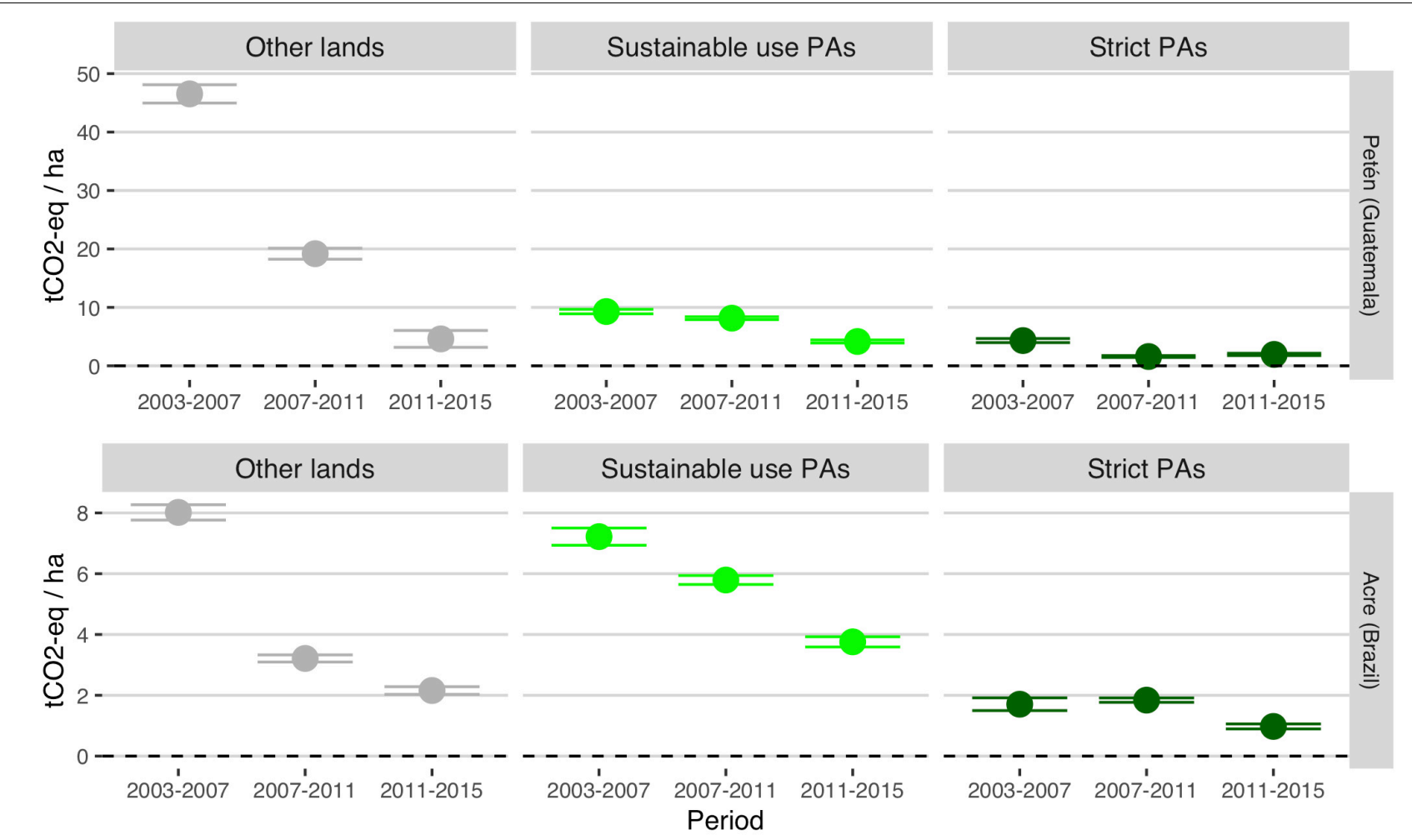

Community Managed PAs relative to: - Other Lands - Sustainable Use PAs - Strict PAs

FIGURE 5 | The temporal effects of Community Managed PAs on avoided carbon emissions in Petén (Guatemala) and Acre (Brazil). Positive temporal effects $(p<0.05)$ indicate net avoided carbon emissions relative to Other Lands (gray), Sustainable Use PAs (light green), and Strict PAs (dark green). Error bars indicate $95 \%$ confidence intervals for temporal effects.

Community Managed PAs' at 1, 5, 10, and $15 \mathrm{~km}$ from their boundaries in the years and periods aforementioned. Overall, both jurisdictions display spatial effects on carbon stocks that partially resemble the temporal effects, where Community Managed PAs effectiveness is more evident over Other Lands and Sustainable Use PAs. However, each jurisdiction corresponds to specific geographical settings.

Regarding Petén, Community Managed PAs do not share boundaries with Other Lands and are embedded inside the Maya Biosphere Reserve (Figure 1). When compared to neighboring Sustainable Use PAs in 2007, Community Managed PAs stored additional carbon stocks between $1.5 \%(1.2 \mathrm{tC} / \mathrm{ha})$ at $1 \mathrm{~km}$ and $\sim 12 \%$ at $15 \mathrm{~km}(8.3 \mathrm{tC} / \mathrm{ha})$ and therefore Effects Ratios between 1.2 and 1.8-fold, respectively (Figures 7, 8). Instead, Community Managed PAs in Petén only stored significantly higher carbon stocks than surrounding Strict PAs at $10 \mathrm{~km}(\sim 4.2 \% ; 3 \mathrm{tC} / \mathrm{ha})$ and $15 \mathrm{~km}$ (8.1\%; $5.8 \mathrm{tC} / \mathrm{ha})$ from their boundaries in 2007, which translate in Effects Ratios of 1.4 and 1.8, respectively. These results imply that Community Managed PAs were $\sim 1.8$ times more likely to store higher carbon stocks than Sustainable Use PAs and Strict PAs at $15 \mathrm{~km}$ in 2007, requiring unobserved covariates with Effects Ratios (i.e., $E$-values) larger than 3 to explain away this association. In both comparisons, the spatial effects increased in 2011, ranging between 0.5 and $2.4 \%$. In
2015 , there were slight variations $(-4 \% ; 7 \%)$ in the spatial effects that usually resulted in larger effects than in 2007. Thus, Community Managed PAs in Petén maintained higher and more stable carbon stocks than their surroundings until 2015 (Supplementary Figure 6).

Acre's Community Managed PAs, which did not share boundaries with Strict PAs in 2003, had significant effects over Other Lands and Sustainable Use PAs that also increased with distance (some Strict PAs were founded after 2003 but were included after 2007 in this analysis) (Figure 7). For instance, these areas stored significantly higher carbon stocks than Other Lands with effects that ranged between $5.6 \%$ at $1 \mathrm{~km}(7 \mathrm{tC} / \mathrm{ha})$ and $15.3 \%$ at $15 \mathrm{~km}(20 \mathrm{tC} / \mathrm{ha})$ in 2007 . However, Community Managed PAs effects over Other Lands and Sustainable Use PAs in Acre decreased and resulted in effects below $10 \mathrm{tC} / \mathrm{ha}$ at $15 \mathrm{~km}$ in 2015. In other words, Community Managed PAs in 2007 were around 1.6 and 2 times more likely to store higher carbon stocks than Sustainable Use PAs and Other Lands at $15 \mathrm{~km}$ (E-values 2.4-3.2) (Figure 8). However, these Effects Ratios dropped to $\sim 1.3$ in 2015 , becoming less robust to unobserved covariates (E-values <1.9). Contrasting Petén, Community Managed PAs' effect in Acre was not significantly different from Strict PAs at $1 \mathrm{~km}$ and $15 \mathrm{~km}$ and was significantly lower at $5 \mathrm{~km}$ and $10 \mathrm{~km}$ in 2007 and 2015. Given the relative stability of carbon 


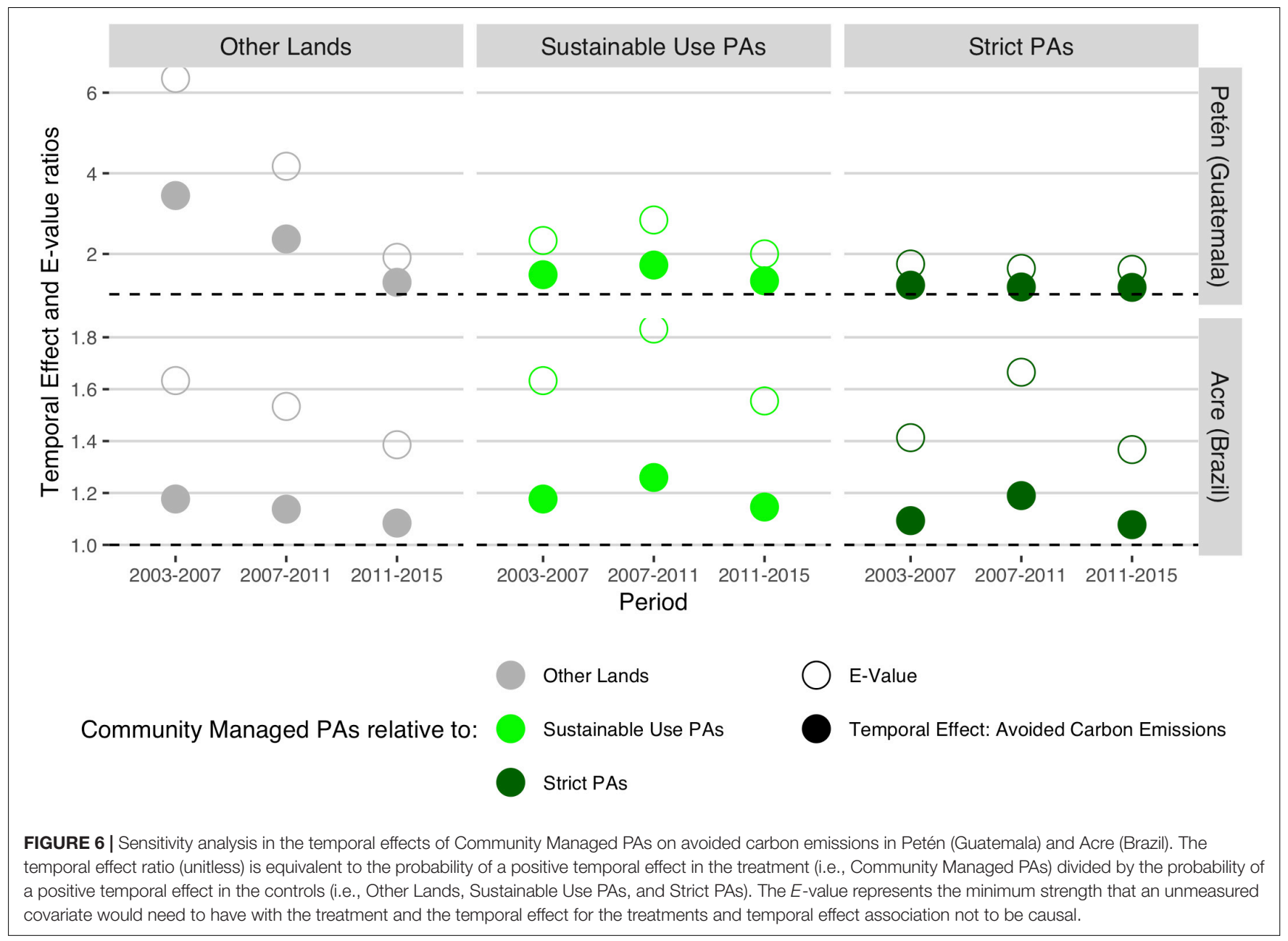

stocks in surrounding land tenures (Supplementary Figure 7), the reducing spatial effects on carbon stocks in Acre seem to be driven by Community Managed PAs. Consequently, except for Strict PAs in Acre, Community Managed PAs tended to store higher carbon stocks than surrounding land tenures. This effect increased and became more robust to unobserved covariates with the distance to boundaries. However, Petén's Community Managed PAs spatial effects remained relatively stable when compared to surrounding lands throughout 2011 and 2015, whereas Acre's resulted less effective during the same period.

Community Managed PAs' spatial effects on avoided emissions partially explain the changing effects on carbon stocks in Petén and Acre (Figure 9). The spatial patterns of avoided emissions in Petén resemble those on carbon stocks. Compared to surrounding Sustainable Use PAs and Strict PAs in the 2003-2007 time period, Community Managed PAs did not significantly avoid more emissions at $1 \mathrm{~km}$ but had significant effects at 10 and $15 \mathrm{~km}$ from their boundaries. For instance, Community Managed PAs avoided around 7.8 (Strict PAs) and $4.1 \mathrm{tCO} 2-\mathrm{eq} / \mathrm{ha}$ (Sustainable Use PAs) at $15 \mathrm{~km}$. During 2007-2011, Community Managed PAs resulted in more avoided emissions than Sustainable Use PAs, resulting in $1 \mathrm{tCO} 2-\mathrm{eq} / \mathrm{ha}$ at $1 \mathrm{~km}$ and $8.1 \mathrm{tCO} 2-\mathrm{eq} / \mathrm{ha}$ at $15 \mathrm{~km}$ from their boundaries.
Relative to Strict PAs, these effects were more moderate in the same period ( $<2$ tCO2-eq/ha). Finally, in 2011-2015, the net avoided emissions inside Community Managed PAs boundaries had a wider range relative to Sustainable Use PAs (1-9 tCO2eq/ha) and increased relative to Strict PAs (1-3.8 tCO2-eq/ha). These spatio-temporal changes in avoided emissions are reflected in stable or even increasing robustness of the effects toward unobserved covariates (Figure 10). In other words, Community Managed PAs' boundaries have robust effects that increased avoided emissions until 2015.

Regarding Acre, the avoided carbon emissions did not necessarily increase within the distance to boundaries. Relative to Other Lands, Community Managed PAs only avoided emissions at $10 \mathrm{~km}(4.4 \mathrm{tCO} 2-\mathrm{eq} / \mathrm{ha})$ and $15 \mathrm{~km}(6.6 \mathrm{tCO} 2-$ eq/ha) from their boundaries in the period 2003-2007. These effects subsequently reduced in 2007-2011, and in 2011-2015 resulted in no significant differences in avoided emissions with Other Lands. Compared to surrounding Sustainable Use PAs, the avoided emissions oscillated throughout the threetime periods. During 2003-2007, Community Managed PAs at 1 and $15 \mathrm{~km}$ avoided around $\sim 0-7.6$ tCO2-eq/ha, 4.2$5.3 \mathrm{tCO} 2-\mathrm{eq} / \mathrm{h}$ in the subsequent period, and $5-8.2 \mathrm{tCO} 2-\mathrm{eq} / \mathrm{h}$ in 2011-2015. Community Managed PAs in Acre avoided more 


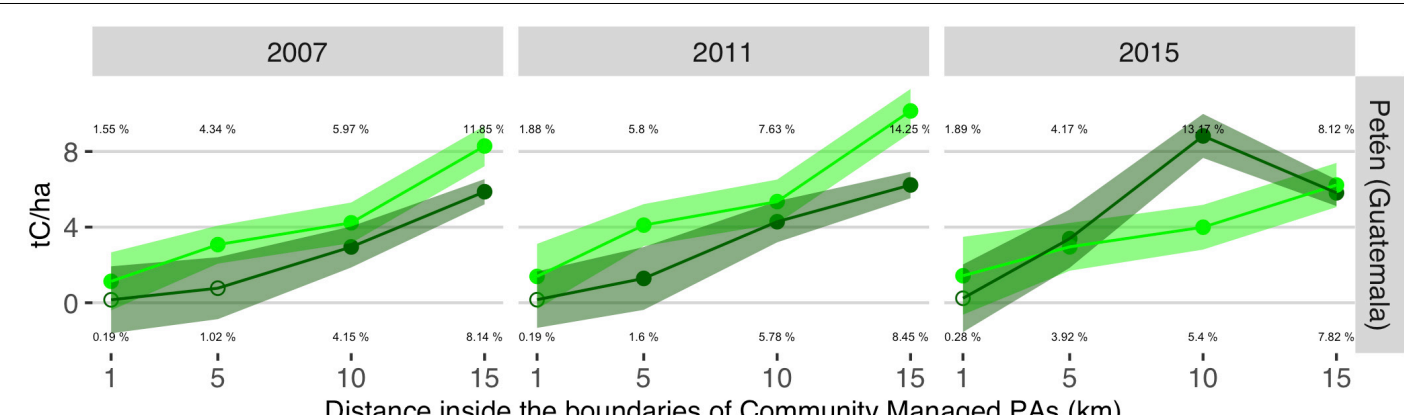

Distance inside the boundaries of Community Managed PAs $(\mathrm{km})$

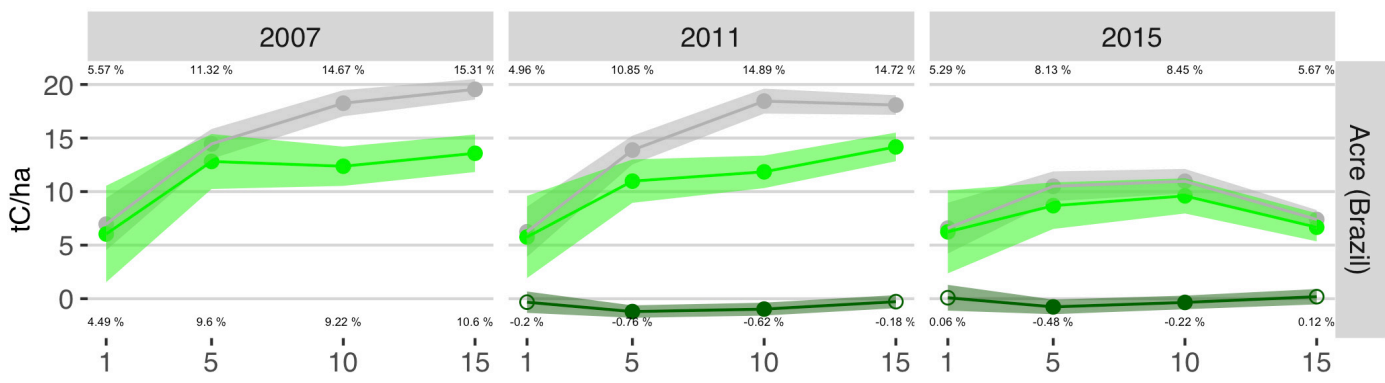

Distance inside the boundaries of Community Managed PAs $(\mathrm{km})$

p Value $\bullet<0.050>=0.05 \quad$ External boundaries $-\rightarrow$ Sustainable Use PAs $\rightarrow$ Strict PAs

FIGURE 7 | The spatial effects of Community Managed PAs on carbon stocks during 2007, 2011, and 2015 in Petén (Guatemala) and Acre (Brazil). The points and percentages are the spatial effects, indicating the additional/fewer carbon stocks secured inside the boundaries of Community Managed PAs relative to Other Lands (gray), Sustainable Use PAs (light green), and Strict PAs (dark green).

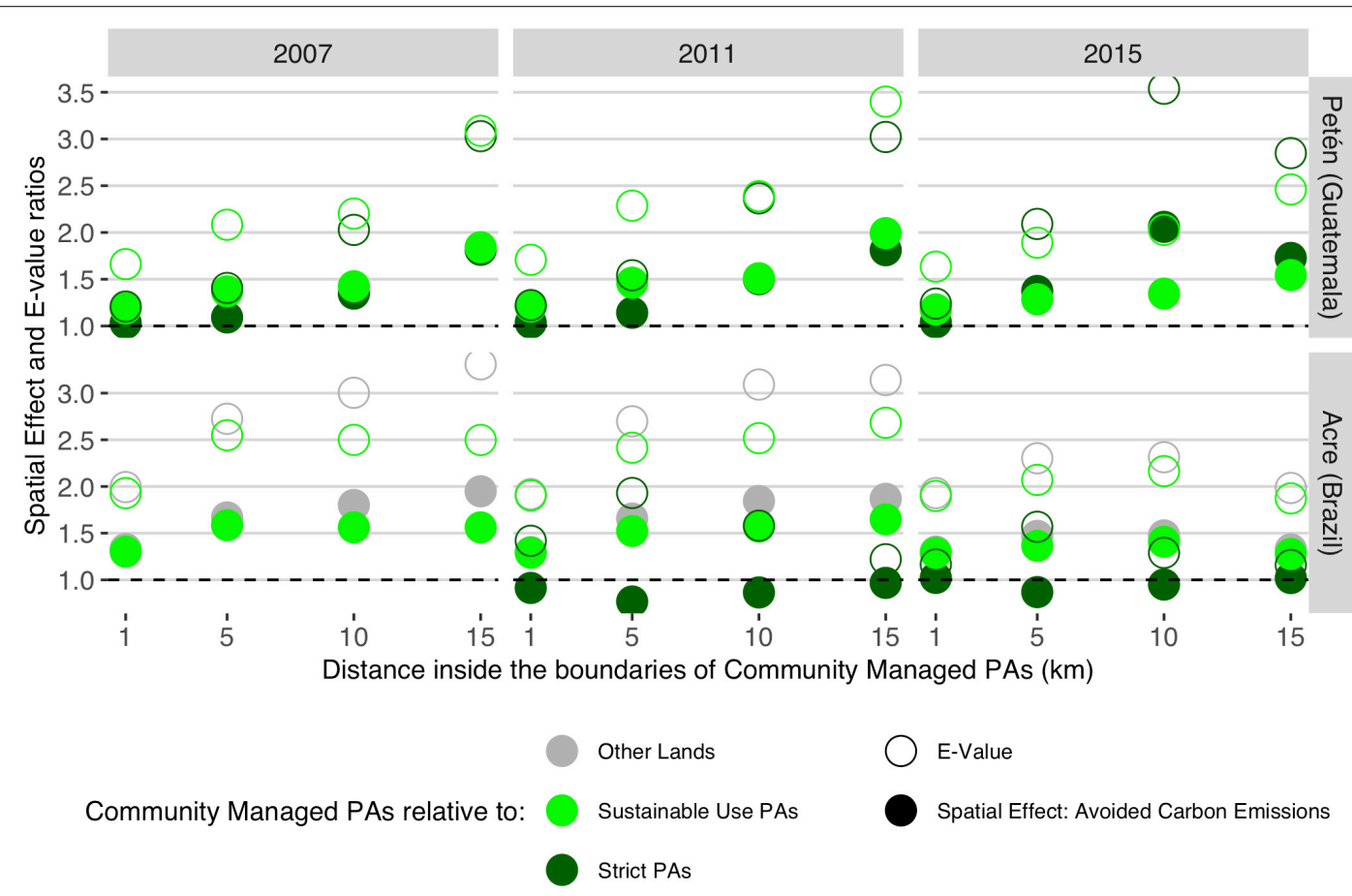

FIGURE 8 | Sensitivity analysis in the spatial effects of Community Managed PAs on carbon stocks in Petén (Guatemala) and Acre (Brazil). The spatial effect ratio (unitless) is equivalent to the probability of a positive spatial effect in the treatment (i.e., Community Managed PAs) divided by the probability of a positive spatial effect in the controls (i.e., Other Lands, Sustainable Use PAs, and Strict PAs). The E-value represents the minimum strength that an unmeasured covariate would need to have with the treatment and the spatial effect for the treatments and spatial effect association not to be causal. 


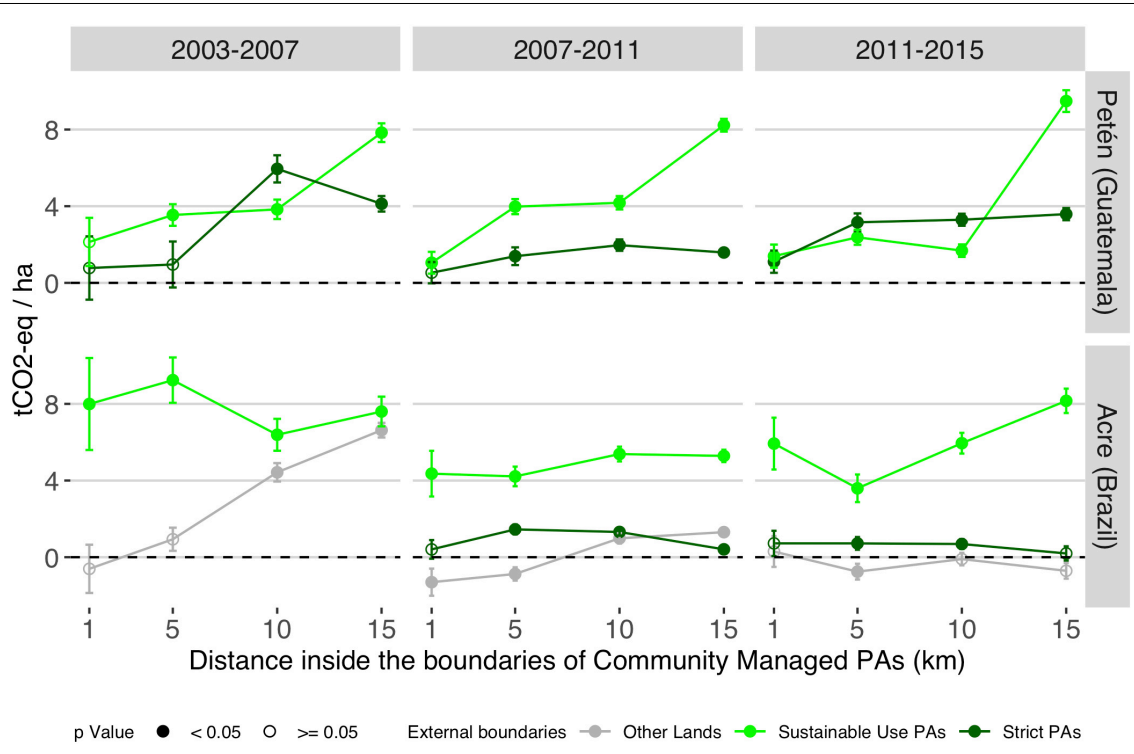

FIGURE 9|The spatial effects of Community Managed PAs on avoided carbon emissions in Petén (Guatemala) and Acre (Brazil). Positive spatial effects indicate net avoided carbon emissions relative to Other Lands (gray), Sustainable Use PAs (light green), and Strict PAs (dark green). Error bars indicate 95\% confidence intervals for temporal effects.

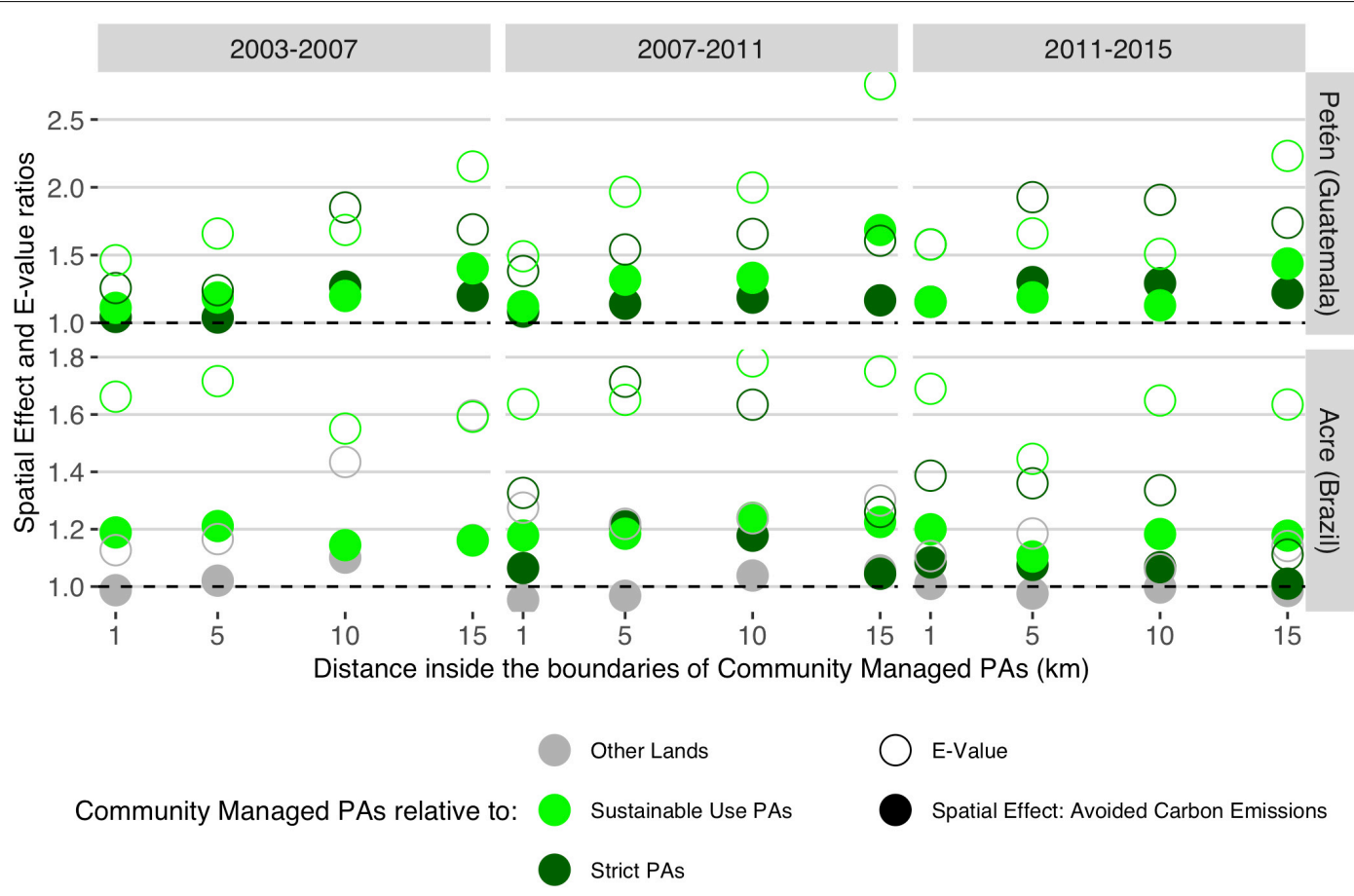

FIGURE 10 | Sensitivity analysis in the spatial effects of Community Managed PAs on avoided carbon emissions in Petén (Guatemala) and Acre (Brazil). The spatial effect ratio (unitless) is equivalent to the probability of a positive spatial effect in the treatment (i.e., Community Managed PAs) divided by the probability of a positive spatial effect in the controls (i.e., Other Lands, Sustainable Use PAs, and Strict PAs). The E-value represents the minimum strength that an unmeasured covariate would need to have with the treatment and the spatial effect for the treatments and spatial effect association not to be causal.

carbon emissions than surrounding Strict PAs in 2007-2011 $(>1.3 \mathrm{tCO} 2$-eq/h) and $2011-2015(>0.7 \mathrm{tCO} 2-\mathrm{eq} / \mathrm{h})$ at 5 and $10 \mathrm{~km}$ from their boundaries, but these effects were the least robust to unobserved covariates in 2011-2015 (e.g., Effects
Ratio $=1.07$ and $E$-value $=1.12$ at $5 \mathrm{~km}$ ). Overall, these results indicate that in both jurisdictions, Community Managed PAs are more effective in avoiding carbon emissions than neighboring Sustainable Use PAs, and Strict PAs, to a lower extent. According 
to the spatial effects on carbon stocks and avoided emissions, the effectiveness of Community Managed PAs' boundaries exhibit differences across jurisdictions. In Petén, as the distance to Community Managed PAs boundaries increase, more emissions are avoided inside, resulting in additional carbon stocks, and usually, more robust effects to unobserved covariates from 2003 until 2015. The results in Acre indicate that Community Managed PA's boundaries have become less effective in avoiding emissions, which translates into reduced carbon stocks, and spatial effects that are more prone to the influence of unobserved covariates.

\section{DISCUSSION}

Our study estimates Community Managed PAs' effect on carbon stocks and avoided carbon emissions in the Department of Petén (Guatemala) and the state of Acre (Brazil). Particularly, we focus on the temporal and spatial effects of Community Concessions in Petén and Extractive Reserves in Acre, relative to Other Lands (i.e., unprotected), other Sustainable Use PAs, and Strict PAs using matching methods and geographic discontinuity designs. Our results highlight that Community Managed PAs not only differ from Other Lands in market access and agriculture suitability but also differ with Sustainable Use PAs (i.e., IUCN V-VI or equivalent) and Strict PAs (i.e., IUCN I-IV). After controlling for these spatial covariates, the results indicate that Community Managed PAs in Petén and Acre effectively maintain carbon stocks and avoid carbon emissions.

\section{The Effectiveness of Community Managed Protected Areas}

The effectiveness of Community Managed PAs on carbon stocks dynamics varied across jurisdictions and land tenures used as counterfactuals. Overall, our results are consistent with earlier studies highlighting the effectiveness of PAs that allow non-industrial extractive activities over Other Lands that lack protection. Compared to Other Lands, and not comparing PAs directly, Nelson and Chomitz (2011) show that Sustainable Use PAs result in lower fire incidence than Strict PAs across Latin America and the Caribbean. This indirect comparison has also established the effectiveness of Community Managed PAs on avoided deforestation (i.e., Community Concessions) in Petén (Blackman, 2015). Our results are consistent with these findings and additionally established that current Community Concessions in Petén are more effective than Sustainable Use PAs and Strict PAs in conserving carbon stocks and avoiding carbon emissions. That is, National Parks, Multiple Use Zones in the Maya Biosphere Reserve (e.g., Cooperatives, revoked concessions) and PAs with IUCN category V-VI across Petén. Similar to Pfaff et al. (2014) and Koskimäki et al. (2021), our results also established that Community Managed PAs (i.e., Extractive Reserves) in Acre (Brazil) have a significant role in forest conservation. Further direct comparisons with multiple land tenures in our study indicate that the greatest impacts of Extractive Reserves on carbon stocks dynamics occur over Other Lands, followed by Sustainable Use PAs (e.g., National Forests, State Forests, Settlements in public forests). Extractive Reserves in
Acre were also more effective than Strict PAs in avoiding carbon emissions, but slightly less effective in storing carbon stocks, and not consistently different from Strict PAs in their vicinity.

However, our results are not consistent with studies that directly compare different categories of PAs. For example, Elleason et al. (2021) found that across the neotropics, Strict PAs have lower deforestation than other PAs. Similarly, Strict PAs in Indonesia, Thailand, and to a limited extent in Bolivia and Costa Rica, result in higher avoided deforestation when they are directly compared to Sustainable Use PAs (Ferraro et al., 2013). This lack of consistency might be explained by two factors in our study design. First, our study is more similar to Andam et al. (2013), which compare Sustainable Use PAs to Other Lands and Strict PAs in terms of avoided deforestation and additional regrowth. By using annual carbon stocks and avoided carbon emissions as outcome variables, our study design provides an integral assessment on Community Managed PAs, reflecting their effectiveness on avoided deforestation, and additionally, on avoided degradation and recovery. Furthermore, regardless of the relative effectiveness of Strict PAs over less strict PAs (here, Sustainable Use and Community Managed PAs), the differences tend to be modest and even statistically insignificant in previous studies and in our own findings. Thus, our results exhibit that Community Managed PAs in Petén and Acre are more effective than Other Lands and Sustainable Use PAs, and at least as effective as Strict PAs, in preserving carbon stocks and avoiding emissions.

\section{Jurisdictional and Local Land-Use Dynamics}

Despite the effectiveness over different land tenures, Community Managed PAs in Petén and Acre exhibit an overall reduction in their capacity to avoid carbon emissions. This reduced capacity does not necessarily imply increasing carbon losses in Community Managed PAs. After controlling for covariates, our results suggest that Other Lands, Sustainable Use PAs, and Strict PAs have reduced and stabilized their carbon emissions, causing more moderate net avoided emissions on Community Managed PAs. Jurisdictional land-use dynamics may explain these reducing spatial effects. Across Petén, extending forests fires and deforestation have been reported since the 1980s (Bray et al., 2008; Radachowsky et al., 2012), and they seem to have increased in the 2000s, followed by a reduction in the early 2010s (Hodgdon et al., 2015; Bullock et al., 2020; Global Forest Watch, 2021). This temporal pattern coincides with the large expansion of oil palm in southern Petén during the 2000s that partially dropped in the 2010s (Hervas, 2021). In Acre, deforestation reached a peak in the early 2000s and then reduced throughout the 2000s and early 2010s (INPE, 2020). The reduction of deforestation in the Brazilian Amazon seems in part explained due to a reduced pressure on old forest frontiers with consolidated rural areas, which corresponds to the northern part of Acre (Schielein and Börner, 2018). Consequently, the reduced effectiveness of Community Managed PAs on avoided carbon emissions in Petén and Acre partially correspond to a jurisdictional-wide reduction in land-use pressure over forests. 
The spatial effects reflect some local land-use dynamics that are not evident in the temporal effects. Petén's Community Managed PAs boundaries have maintained larger carbon stocks and avoid more emissions compared to neighboring Sustainable Use PAs and Strict PAs between 2003 and 2015. According to Devine et al. (2020), Laguna del Tigre National Park (Strict PA) and Multiple Use Zones (Sustainable Use PAs) that share boundaries with some Community Managed PAs have been subject to forest clearing, land speculation, and land grabbing. Acre's Community Managed PAs between 2007 and 2015 reduced their effect on carbon stocks and avoided emissions, which contrasts with relatively stable carbon dynamics in Other Lands and Sustainable Use PAs in their vicinity. This reduced effectiveness is directly attributable to Community Managed PAs and might be explained by the diversification of income activities. Traditionally, households in Acre's Community Managed PAs relied on the extraction of natural rubber $(H$. brasiliensis) and Brazil nut ( $B$. excelsa) but have recently incorporated cattle ranching (Duchelle et al., 2014; Maciel et al., 2018; Kröger, 2020), potentially increasing carbon emissions and reducing carbon stocks. Our results highlight the need for temporal and spatial effects for integral assessments. While the temporal effects may exhibit overall land-use dynamics across a jurisdiction, the spatial effects evidence local land-use pressures emerging inside or around the boundaries of Community Managed PAs.

\section{Community Managed Protected Areas and REDD+}

In Petén and Acre, Community Managed PAs' effects on carbon stocks dynamics can also be interpreted in the context of governance and REDD + . ACOFOP, which associates Community Concessions in Petén, became a bridging social organization that has facilitated support relations with NGOs, certification programs, and government agencies (Taylor, 2012; Butler and Current, 2021). These support relations have resulted in a governance system with transparent management plans, wide local representation, and diversified forest activities that include timber, non-timber forest products, and in some cases, tourism (Millner et al., 2020). Regarding Acre, the rubber tappers organization has redefined itself as one of extractive populations after years of articulation with diverse social organizations from the Brazilian Amazon (Gomes et al., 2018). This bridging social organization became a platform to actively participate in State and Federal policies, especially between the 1990s and 2000s, resulting in the increase of Extractive Reserves and securing subsistence activities of forest extractivists households that are required to maintain $90 \%$ of forest cover from their landholdings (Gomes et al., 2018). We infer from our results that these bridging social organizations have a major role in carbon stock dynamics and drive Community Managed PAs' governance systems in Petén and Acre.

These dynamic governance systems have contributed to the creation of GuateCarbon in Petén (Hodgdon et al., 2013) and SISA in Acre (Rosa Da Conceição and Börner, 2020), which exhibit two different REDD+ models. GuateCarbon is a local REDD+ program aiming to generate carbon credits in voluntary markets (Hodgdon et al., 2013). SISA is a jurisdictional initiative that includes multiple environmental policies, including a REDD+ program (ISA-Carbono) that integrates international funding bodies, a recipient state (Acre), and multiple local stakeholders (Sills et al., 2014; Sunderlin et al., 2015). Using multiple (i.e., Other Lands, Sustainable Use PAs, and Strict PAs) and conservative baselines (i.e., controlling for agricultural suitability and market access), our results indicate that Community Managed PAs in Petén and Acre were effective in avoiding emissions from deforestation and degradation before and after these initiatives began to operate.

However, according to our results, Community Managed PAs net avoided emissions reduced after GuateCarbon and SISA began to operate, questioning the additionality of these REDD+ projects. As explained above, there was an overall reduction in avoided emissions outside Community Managed PAs in Petén and Acre. Moreover, it is worth noting that our results are not meant to coincide with the baselines or emissions targets established by GuateCarbon or ISA-Carbono. Estimating temporal and spatial effects through matching analysis and geographic discontinuity designs provide conservative estimates that tend to exclude core areas with the most stable and higher carbon stocks (Alejo et al., 2021). In fact, before controlling for market access and agriculture suitability covariates, Community Concessions in Petén displayed an increase in carbon stocks after GuateCarbon began. Similarly, carbon stocks in Extractive Reserves from Acre have remained stable since 2003. In Acre, SISA has maintained previous initiatives that benefited communities in Extractive Reserves, such as the rubber-tapper subsidy program (Rosa Da Conceição and Börner, 2020), and implemented others with small colonist farmers and cattle ranchers (Sills et al., 2014). Our results suggest that SISA may have partially influenced an overall reduction in landuse emissions in Acre. Considering that ISA-Carbono remains in the initial stages of implementation (Rosa Da Conceição and Börner, 2020), it is early to establish the additionality of this REDD+ project. Hence, our results highlight that forest communities with bridging social organizations supported by government institutions and international organizations (e.g., NGOs, international aid) may contribute to climate change mitigation and forest conservation targets, like those envisioned by GuateCarbon and SISA. Finally, we also identified that Community Managed PAs conserve considerable amounts of carbon stocks. While the conservation and enhancement of carbon stocks have not been clarified by the UNFCCC, our results also highlight the need to include these activities in REDD+'s portfolio (Funk et al., 2019).

\section{Study Limitations}

While we consider that this study offers an integral assessment of Community Managed PAs on carbon stocks dynamics, four limitations should be noted. First, Community Managed PAs represent a diverse group of forest communities with particular land-use dynamics. Previous studies have shown the differences among past-resident, new-resident, and non-resident Community Concessions in Petén (Radachowsky et al., 2012; Taylor, 2012; Blackman, 2015). Our study focuses on those 
concessions that remained active and certified, mostly pastresident and non-resident communities, that became proponents of the REDD+ program GuateCarbon (Hodgdon et al., 2013). Second, our study does not distinguish carbon emissions from deforestation and degradation. According to Bullock et al. (2020), deforestation is more prevalent than degradation in Petén. Oppositely, carbon emissions in PAs from the Brazilian Amazon are dominated by degradation (Kruid et al., 2021). Future quasiexperimental studies controlling for spatial location covariates may benefit from distinguishing the role of deforestation and degradation in Community Managed PAs. Third, our study assesses Community Managed PAs in terms of an ecological indicator (i.e., carbon stocks). Other studies also explore the role of PAs in terms of poverty, income, and livelihoods (e.g., Duchelle et al., 2014; Miranda et al., 2016; Bocci et al., 2018). In addition to these indicators of ecological and social "success," Community Managed PAs need to be evaluated in terms of tenure security (Robinson et al., 2014) and participation across genders, classes, and ethnicity (Millner et al., 2020). Fourth, the time frame of our study does not cover the last 5 years that display an upturn in deforestation and forest degradation in Guatemala and Brazil (Bullock et al., 2020; Kruid et al., 2021), which could deeply influence the role of Community Managed PAs in climate change mitigation.

\section{CONCLUSION}

Community Managed PAs represent a unique form of forest governance, as they aim to reconcile conservation, climate change mitigation, and local livelihoods. Our study expanded the methodological scope of previous studies and assessed the role of Community Managed PAs on carbon dynamics relative to different land tenures. Using both temporal and spatial assessments, we found that Community Concessions in Petén (Guatemala) and Extractive Reserves in Acre (Brazil), two forms of Community Managed PAs, are effective in conserving carbon stocks and avoiding carbon emissions. Moreover, these Community Managed PAs were more effective than Other Lands (i.e., unprotected) and Sustainable Use PAs (i.e., IUCN $\mathrm{V}$-VI or equivalent), and at least as effective as Strict PAs (i.e., IUCN I-IV or equivalent). Our findings illustrate that estimating temporal and spatial effects are key to distinguish local and jurisdiction-wide land-use dynamics among land tenures. We also make further progress toward confirming

\section{REFERENCES}

Agrawal, A., Chhatre, A., and Hardin, R. (2008). Changing governance of the world's forests. Science 320, 1460-1462. doi: 10.1126/science.1155369

Alejo, C., Meyer, C., Walker, W. S., Gorelik, S. R., Josse, C., Aragon-Osejo, J. L., et al. (2021). Are indigenous territories effective natural climate solutions? A neotropical analysis using matching methods and geographic discontinuity designs. PLoS One 16:e245110. doi: 10.1371/journal.pone.0245110

Andam, K. S., Ferraro, P. J., and Hanauer, M. M. (2013). The effects of protected area systems on ecosystem restoration: a quasi-experimental design to estimate the impact of Costa Rica's protected area system on forest regrowth. Conserv. Lett. 6, 317-323. doi: 10.1111/conl.12004 that decentralized governance may help PAs reach ecological and social targets. That is particularly relevant in the context of REDD+ as we show that when social organizations of forest communities build support relations with government institutions and international organizations, they may improve forest governance and contribute to climate change mitigation.

\section{DATA AVAILABILITY STATEMENT}

The datasets presented in this study can be found in online repositories. The names of the repositories and accession numbers can be found in the article. The original contributions presented in the study are publicly available. These data can be found here: https://osf.io/ejavd/.

\section{AUTHOR CONTRIBUTIONS}

All authors contributed to the conception and design of the study. CA, WW, and SG participated in data curation. CA performed the statistical analyses and wrote the sections of the manuscript. All authors contributed to the manuscript revision, read, and approved the submitted version.

\section{FUNDING}

CA received funding from the Natural Sciences and Engineering Research Council of Canada (NSERC) CREATE program Biodiversity, Ecosystem Services and Sustainability (BESS).

\section{ACKNOWLEDGMENTS}

We thank the reviewers, Oliver T. Coomes, Frédéric Guichard, Margaret Kalacska, and Cristopher Luederitz for valuable comments and suggestions.

\section{SUPPLEMENTARY MATERIAL}

The Supplementary Material for this article can be found online at: https://www.frontiersin.org/articles/10.3389/ffgc.2022. 787978/full\#supplementary-material

Baccini, A., Goetz, S. J., Walker, W. S., Laporte, N. T., Sun, M., Sulla-Menashe, D., et al. (2012). Estimated carbon dioxide emissions from tropical deforestation improved by carbon-density maps. Nat. Clim. Change 2, 182-185. doi: 10.1038/ nclimate 1354

Baccini, A., Walker, W., Carvalho, L. E., Farina, M. K., Solvik, K. K., and SullaMenashe, D. (2021). Aboveground Biomass Change for Amazon Basin, Mexico, and Pantropical Belt, 2003-2016. Oak Ridge, Ten: ORNL DAAC, doi: 10.3334/ ORNLDAAC/1824

Baccini, A., Walker, W., Carvalho, L., Farina, M., Sulla-Menashe, D., and Houghton, R. A. (2017). Tropical forests are a net carbon source based on aboveground measurements of gain and loss. Science 358, 230-234. doi: 10. 1126/science.aam5962 
Baragwanath, K., and Bayi, E. (2020). Collective property rights reduce deforestation in the Brazilian Amazon. Proc. Natl. Acad. Sci. U.S.A. 117, 20495-20502. doi: 10.1073/pnas.1917874117

Blackman, A. (2015). Strict versus mixed-use protected areas: Guatemala's Maya biosphere reserve. Ecol. Econ. 112, 14-24. doi: 10.1016/j.ecolecon.2015.0 1.009

Blackman, A., and Veit, P. (2018). Titled amazon indigenous communities cut forest carbon emissions. Ecol. Econ. 153, 56-67. doi: 10.1016/j.ecolecon.2018. 06.016

Blackman, A., Pfaff, A., and Robalino, J. (2015). Paper park performance: Mexico's natural protected areas in the 1990s. Glob. Environ. Change 31, 50-61. doi: 10.1016/j.gloenvcha.2014.12.004

Bocci, C., Fortmann, L., Sohngen, B., and Milian, B. (2018). The impact of community forest concessions on income: an analysis of communities in the Maya biosphere reserve. World Dev. 107, 10-21. doi: 10.1016/j.worlddev.2018. 02.011

Bonilla-Mejía, L., and Higuera-Mendieta, I. (2019). Protected areas under weak institutions: evidence from Colombia'. World Dev. 122, 585-596. doi: 10.1016/ j.worlddev.2019.06.019

Börner, J., Schulz, D., Wunder, S., and Pfaff, A. (2020). The effectiveness of forest conservation policies and programs. Ann. Rev. Resour. Econ. 12, 45-64. doi: 10.1146/annurev-resource-110119-025703

Bray, D. B., Duran, E., Ramos, V. H., Mas, J. F., Velazquez, A., McNab, R. B., et al. (2008). Tropical deforestation, community forests, and protected areas in the Maya Forest. Ecol. Soc. 13:56. doi: 10.5751/ES-02593-130256

Bullock, E. L., Nolte, C., Segovia, A. R., and Woodcock, C. E. (2020). Ongoing forest disturbance in Guatemala's protected areas. Remote Sens. Ecol. Conserv. 6, 141-152. doi: 10.1002/rse2.130

Butler, M., and Current, D. (2021). A comparative analysis of community-based enterprise governance in the Maya Biosphere Reserve. Soc. Nat. Resour. 34, 1449-1471. doi: 10.1080/08941920.2021.1965272

Cronkleton, P., Taylor, P. L., Barry, D., Stone-Jovicich, S., and Schmink, M. (2008). Environmental Governance and the Emergence of Forest-Based Social Movements. CIFOR Occasional Paper No.49. Bogor: Center for International Forestry Research (CIFOR), doi: 10.17528/cifor/002348

Devine, J. A., Currit, N., Reygadas, Y., Liller, L. I., and Allen, G. (2020). Drug trafficking, cattle ranching and land use and land cover change in Guatemala's Maya Biosphere Reserve. Land Use Policy 95:104578. doi: 10.1016/j.landusepol. 2020.104578

Diamond, A., and Sekhon, J. (2012). Genetic matching for estimating causal effects. Rev. Econ. Stat. 95, 932-945. doi: 10.1162/REST_a_00318

Duchelle, A. E., Almeyda Zambrano, A. M., Wunder, S., Börner, J., and Kainer, K. A. (2014). Smallholder specialization strategies along the forest transition curve in Southwestern Amazonia. World Dev. 64, S149-S158. doi: 10.1016/j. worlddev.2014.03.001

Dudley, N., Parrish, J. D., Redford, K. H., and Stolton, S. (2010). The revised IUCN protected area management categories: the debate and ways forward. Oryx 44, 485-490. doi: 10.1017/S0030605310000566

Elleason, M., Guan, Z., Deng, Y., Jiang, A., Goodale, E., and Mammides, C. (2021). Strictly protected areas are not necessarily more effective than areas in which multiple human uses are permitted. Ambio 50, 1058-1073. doi: 10.1007/s13280020-01426-5

Ferraro, P. J., Hanauer, M. M., Miteva, D. A., Canavire-Bacarreza, G. J., Pattanayak, S. K., and Sims, K. R. E. (2013). More strictly protected areas are not necessarily more protective: evidence from Bolivia, Costa Rica, Indonesia, and Thailand. Environ. Res. Lett. 8:025011. doi: 10.1088/1748-9326/8/2/025011

Fick, S. E., and Hijmans, R. J. (2017). WorldClim 2: new 1-km spatial resolution climate surfaces for global land areas. Int. J. Climatol. 37, 4302-4315. doi: $10.1002 /$ joc. 5086

Fick, S. E., and Hijmans, R. J. (2020). WorldClim 2.1, Historical Climate Data. Available online at: https://www.worldclim.org/data/worldclim21.html (accessed June 28, 2021)

Funk, J. M., Aguilar-Amuchastegui, N., Baldwin-Cantello, W., Busch, J., Chuvasov, E., Evans, T., et al. (2019). Securing the climate benefits of stable forests. Clim. Policy 19, 845-860. doi: 10.1080/14693062.2019.1598838

Global Forest Watch. (2021). Petén, Guatemala Deforestation Rates \& Statistics | GFW. Available online at: https://www.globalforestwatch. org/dashboards/country/GTM/12/?category=summary\&dashboardPrompts=
eyJzaG93UHJvbXB0cyI6dHJ1ZSwicHJvbXB0c1ZpZXdlZCI6W10sInNldHRpb mdzIjp7Im9wZW4iOmZhbHNILCJzdGVwSW5kZXgiOjAsInN0ZXBzS2V5Ijo iIn0sIm9wZW4iOnRydWUsInN0ZXBzS2V5IjoiZGFz (accessed September, 11 2021)

Gomes, C. V. A., Alencar, A., Vadjunec, J. M., and Pacheco, L. M. (2018). Extractive reserves in the Brazilian Amazon thirty years after Chico Mendes: social movement achievements, territorial expansion and continuing struggles. Desenvolv. Meio Ambiente 48, 74-98. doi: 10.5380/dma.v48i0. 58830

Greifer, N. (2021). Package "cobalt". Available online at: https://cran.r-project.org/ web/packages/cobalt/cobalt.pdf (accessed January 19, 2022).

Hervas, A. (2021). Mapping oil palm-related land use change in Guatemala, 20032019: implications for food security. Land Use Policy 109:105657. doi: 10.1016/ j.landusepol.2021.105657

Ho, D. E., Imai, K., King, G., and Stuart, E. A. (2015). MatchIt: nonparametric preprocessing for parametric causal inference. J. Stat. Softw. 42, 1-28. doi: 10.18637/jss.v042.i08

Hodgdon, B. D., Hayward, J., and Samayoa, O. (2013). Putting the plus first: community forest enterprise as the platform for REDD+ in the Maya biosphere reserve, Guatemala. Trop. Conserv. Sci. 6, 365-383. doi: 10.1177/ 194008291300600305

Hodgdon, B. D., Hughell, D., Ramos, V. H., Balas, and McNab, R. (2015). Deforestation Trends in the Maya Biosphere Reserve, Guatemala. Available online at: https://www.rainforest-alliance.org/wp-content/uploads/2021/07/ MBR-Deforestation-Trends.pdf (accessed February 4, 2022).

Iacus, S. M., King, G., and Porro, G. (2015). cem: software for coarsened exact matching. J. Stat. Softw. 30, 1-27. doi: 10.18637/jss.v030.i09

IMC (2020). Program for Pioneers in REDD+ (REM), Estado do Acre. Available online at: http://imc.ac.gov.br/programa-para-pioneiros-em-redd$\mathrm{rem} /$ (accessed January 11, 2022)

INPE (2020). PRODES, Monitoramento do Desmatamento da Floresta Amazônica Brasileira por Satélite. Available online at: http://www.obt.inpe.br/OBT/ assuntos/programas/amazonia/prodes (accessed September 11, 2021)

Jarvis, A., Reuter, H. I., Nelson, A., and Guevara, E. (2008). Hole-filled seamless SRTM data V4, International Centre for Tropical Agriculture (CIAT). Available online at: https://srtm.csi.cgiar.org (accessed July 10, 2021).

Joppa, L. N., and Pfaff, A. (2009). High and far: biases in the location of protected areas. PLoS One 4:e8273. doi: 10.1371/journal.pone.0008273

Joppa, L. N., and Pfaff, A. (2010). Reassessing the forest impacts of protection: the challenge of nonrandom location and a corrective method. Ann. N. Y. Acad. Sci. 1185, 135-149. doi: 10.1111/j.1749-6632.2009.05162.x

Joppa, L. N., Loarie, S. R., and Pimm, S. L. (2008). On the protection of "protected areas". Proc. Natl. Acad. Sci. U.S.A. 105, 6673-6678. doi: 10.1073/ pnas. 0802471105

Jusys, T. (2018). Changing patterns in deforestation avoidance by different protection types in the Brazilian Amazon. PLoS One 13:e0195900. doi: 10.1371/ journal.pone. 0195900

Keele, L. J., and Titiunik, R. (2015). Geographic boundaries as regression discontinuities. Polit. Anal. 23, 127-155. doi: 10.1093/pan/mpu014

Keele, L. J., Titiunik, R., and Zubizarreta, J. R. (2015). Enhancing a geographic regression discontinuity design through matching to estimate the effect of ballot initiatives on voter turnout. J. R. Stat. Soc. Ser. A Stat. Soc. 178, 223-239. doi: 10.1111/rssa.12056

Koskimäki, T., Eklund, J., Moulatlet, G. M., and Tuomisto, H. (2021). Impact of individual protected areas on deforestation and carbon emissions in Acre, Brazil. Environ. Conserv. 48, 217-224. doi: 10.1017/S0376892921000229

Kröger, M. (2020). Deforestation, cattle capitalism and neodevelopmentalism in the Chico Mendes Extractive Reserve, Brazil. J. Peasant Stud. 47, 464-482. doi: $10.1080 / 03066150.2019 .1604510$

Kruid, S., Macedo, M. N., Gorelik, S. R., Walker, W., Moutinho, P., Brando, P. M., et al. (2021). Beyond deforestation: carbon emissions from land grabbing and forest degradation in the Brazilian Amazon. Front. For. Glob. Change 4:645282. doi: $10.3389 /$ ffgc. 2021.645282

Liu, W., Kuramoto, S. J., and Stuart, E. A. (2013). An introduction to sensitivity analysis for unobserved confounding in nonexperimental prevention research. Prev. Sci. 14, 570-580. doi: 10.1007/s11121-012-0339-5

Maciel, R. C. G., Cavalcanti, F. C., da, S., de Souza, E. F., de Oliveira, O. F., and Cavalcante Filho, P. G. (2018). The "Chico Mendes" extractive reserve and land 
governance in the Amazon: some lessons from the two last decades. J. Environ. Manag. 223, 403-408. doi: 10.1016/j.jenvman.2018.06.064

MacKinnon, K., Dudley, N., and Sandwith, T. (2011). Natural solutions: protected areas helping people to cope with climate change. Oryx 45, 461-462. doi: 10 . 1017/S0030605311001608

Mathur, M. B., Smith, L. H., Peng, D., and VanderWeele, T. J. (2021). Package "EValue". Available online at: https://cran.r-project.org/web/packages/EValue/ EValue.pdf (accessed October 28, 2021).

Millner, N., Peñagaricano, I., Fernandez, M., and Snook, L. K. (2020). The politics of participation: negotiating relationships through community forestry in the Maya Biosphere Reserve, Guatemala. World Dev. 127:104743. doi: 10.1016/j. worlddev.2019.104743

Miranda, J. J., Corral, L., Blackman, A., Asner, G., and Lima, E. (2016). Effects of protected areas on forest cover change and local communities: evidence from the Peruvian Amazon. World Dev. 78, 288-307. doi: 10.1016/j.worlddev.2015. 10.026

Negret, P. J., Di-Marco, M., Sonter, L. J., Rhodes, J., Possingham, H. P., and Maron, M. (2020). Effects of spatial autocorrelation and sampling design on estimates of protected area effectiveness. Conserv. Biol. 34, 1452-1462. doi: 10.1111/cobi. 13522

Nelson, A. (2008). Travel Time to Major Cities: A Global Map of Accessibility., Global Environment Monitoring Unit - Joint Research Centre of the European Commission, Ispra Italy. Available online at: https://forobs.jrc.ec.europa.eu/ products/gam/download.php (accessed February 4, 2022).

Nelson, A., and Chomitz, K. M. (2011). Effectiveness of strict vs. multiple use protected areas in reducing tropical forest fires: a global analysis using matching methods. PLoS One 6:e22722. doi: 10.1371/journal.pone.002 2722

Nolte, C., Agrawal, A., Silvius, K. M., and Britaldo, S. S. F. (2013). Governance regime and location influence avoided deforestation success of protected areas in the Brazilian Amazon. Proc. Natl. Acad. Sci. U.S. A. 110, 4956-4961. doi: 10.1073/pnas.1214786110

Olson, D. M., Dinerstein, E., Wikramanayake, E. D., Burgess, N. D., Powell, G. V. N., Underwood, E. C., et al. (2001). Terrestrial ecoregions of the world: a new map of life on Earth. Bioscience 51, 933-938. doi: 10.1641/0006-3568(2001) 051[0933:teotwa] 2.0.co;2

Pebesma, E., Bivand, R., Racine, E., Sumner, M., Cook, I., Keitt, T., et al. (2021a). Package "sf". Available online at: https://cran.r-project.org/web/packages/sf/sf. pdf (accessed December 17, 2021).

Pebesma, E., Summer, M., Racine, E., Fantini, A., and Blodgett, D. (2021b). Package "Stars". Available online at: https://cran.r-project.org/web/packages/stars/stars. pdf (accessed December 19, 2021).

Pfaff, A., Robalino, J., Herrera, D., and Sandoval, C. (2015a). Protected areas?impacts on Brazilian Amazon deforestation: examining conservation development interactions to inform planning. PLoS One 10:e0129460. doi: 10. 1371/journal.pone.0129460

Pfaff, A., Robalino, J., Lima, E., Sandoval, C., and Herrera, L. D. (2014). Governance, location and avoided deforestation from protected areas: greater restrictions can have lower impact, due to differences in location. World Dev. 55, 7-20. doi: 10.1016/j.worlddev.2013.01.011

Pfaff, A., Robalino, J., Sandoval, C., and Herrera, D. (2015b). Protected area types, strategies and impacts in Brazil's Amazon: public protected area strategies do not yield a consistent ranking of protected area types by impact. Philos. Trans. R. Soc. B Biol. Sci. 370:20140273. doi: 10.1098/rstb.2014. 0273

R Core Team. (2021). R: A Language and Environment for Statistical Computing. Vienna: R Foundation for Statistical Computing.

Radachowsky, J., Ramos, V. H., McNab, R., Baur, E. H., and Kazakov, N. (2012). Forest concessions in the Maya Biosphere Reserve, Guatemala: a decade later. For. Ecol. Manag. 268, 18-28. doi: 10.1016/j.foreco.2011.08.043

Reuter, H. I., Nelson, A., and Jarvis, A. (2007). An evaluation of void-filling interpolation methods for SRTM data. Int. J. Geogr. Inf. Sci. 21, 983-1008. doi: 10.1080/13658810601169899

Robinson, B. E., Holland, M. B., and Naughton-Treves, L. (2014). Does secure land tenure save forests? A meta-analysis of the relationship between land tenure and tropical deforestation. Glob. Environ. Change 29, 281-293. doi: 10.1016/j. gloenvcha.2013.05.012

Rosa Da Conceição, H., and Börner, J. (2020). “Understanding adoption and design of incentive-based forest conservation policies: a case study of the SISA program in Acre, Brazil," in Ecological Economic and Socio Ecological Strategies for Forest Conservation, eds F. Fuders and P. Donoso (Cham: Springer International Publishing), 241-258. doi: 10.1007/978-3-030-35379-7_13

Schielein, J., and Börner, J. (2018). Recent transformations of land-use and landcover dynamics across different deforestation frontiers in the Brazilian Amazon. Land Use Policy 76, 81-94. doi: 10.1016/j.landusepol.2018.04.052

Serviço Florestal Brasileiro. (2020). Cadastro Nacional de Florestas Públicas. Available online at: https://www.florestal.gov.br/cadastro-nacional-deflorestas-publicas (accessed September 2, 2021)

Sills, E. O., Atmadja, S. S., de Sassi, C., Duchelle, A. E., Kweka, D., Resosudarmo, I. A. P., et al. (2014). REDD+ on the Ground: A Case Book of Subnational Initiatives Across the Globe, REDD+ on the Ground: A Case Book of Subnational Initiatives Across the Globe. Bogor: Center for International Forestry Research (CIFOR), doi: 10.17528/cifor/005202

Stuart, E. A. (2010). Matching methods for causal inference: a review and a look forward. Stat. Sci. 25, 1-21. doi: 10.1214/09-STS313

Sunderlin, W. D., Sills, E. O., Duchelle, A. E., Ekaputri, A. D., Kweka, D., Toniolo, M. A., et al. (2015). REDD+ at a critical juncture: assessing the limits of polycentric governance for achieving climate change mitigation. Int. For. Rev. 17, 400-413. doi: 10.1505/146554815817476468

Taylor, P. L. (2012). Multiple forest activities, multiple purpose organizations: organizing for complexity in a grassroots movement in Guatemala’s Petén. For. Ecol. Manag. 268, 29-38. doi: 10.1016/j.foreco.2011.05.007

UNEP-WCMC, and IUCN. (2021). Protected Planet: The World Database on Protected Areas (WDPA). Available online at: www.protectedplanet.net (accessed May 6, 2021).

VanderWeele, T. J., and Ding, P. (2017). Sensitivity analysis in observational research: introducing the E-Value. Ann. Int. Med. 167:268. doi: 10.7326/M162607

Verra. (2017). Reduced Emissions from Avoided Deforestation in the Multiple Use Zone of the Maya Biosphere in Guatemala (Guatecarbon), Verra Project Database. Available online at: http://www.vcsprojectdatabase.org/\#/project_ details/1384 (accessed September 11, 2021).

Walker, W. S., Gorelik, S. R., Baccini, A., Aragon-Osejo, J. L., Josse, C., Meyer, C., et al. (2020). The role of forest conversion, degradation, and disturbance in the carbon dynamics of Amazon indigenous territories and protected areas. Proc. Natl. Acad. Sci. U.S.A. 117, 3015-3025. doi: 10.1073/pnas.1913321117

Weiss, D. J., Nelson, A., Gibson, H. S., Temperley, W., Peedell, S., Lieber, A., et al. (2018). A global map of travel time to cities to assess inequalities in accessibility in 2015. Nature 553, 333-336. doi: 10.1038/nature25181

Worldpop and Center for International Earth Science Information Network (CIESIN). (2020). WorldPop, Global High Resolution Population Denominators Project - Funded by The Bill and Melinda Gates Foundation (OPP1134076). doi: 10.5258/SOTON/WP00675

Conflict of Interest: The authors declare that the research was conducted in the absence of any commercial or financial relationships that could be construed as a potential conflict of interest.

Publisher's Note: All claims expressed in this article are solely those of the authors and do not necessarily represent those of their affiliated organizations, or those of the publisher, the editors and the reviewers. Any product that may be evaluated in this article, or claim that may be made by its manufacturer, is not guaranteed or endorsed by the publisher.

Copyright (c) 2022 Alejo, Walker, Gorelik and Potvin. This is an open-access article distributed under the terms of the Creative Commons Attribution License (CC BY). The use, distribution or reproduction in other forums is permitted, provided the original author(s) and the copyright owner(s) are credited and that the original publication in this journal is cited, in accordance with accepted academic practice. No use, distribution or reproduction is permitted which does not comply with these terms. 